\title{
Overcoming rituximab drug-resistance by the genetically engineered anti-CD20-hIFN- $\alpha$ fusion protein: Direct cytotoxicity and synergy with chemotherapy
}

\author{
GABRIEL G. VEGA ${ }^{1}$, LUZ ARELI FRANCO-CEA ${ }^{1}$, SARA HUERTA-YEPEZ ${ }^{2}$, HÉCTOR MAYANI ${ }^{1}$, \\ SHERIE L. MORRISON ${ }^{3}$, BENJAMIN BONAVIDA $^{3 *}$ and MARIO I. VEGA ${ }^{1-3^{*}}$ \\ ${ }^{1}$ Oncology Research Unit, Oncology Hospital Siglo XXI National Medical Center, IMSS; ${ }^{2}$ Unidad de Investigación \\ en Enfermedades Oncológicas, Hospital Infantil de México 'Federico Gómez', Mexico City 06720, Mexico; \\ ${ }^{3}$ Department of Microbiology, Immunology and Molecular Genetics, Jonsson Comprehensive Cancer Center \\ and David Geffen School of Medicine, University of California at Los Angeles, Los Angeles, CA 90095, USA
}

Received July 8, 2015; Accepted August 4, 2015

DOI: 10.3892/ijo.2015.3170

\begin{abstract}
Treatment of patients with B-NHL with rituximab and $\mathrm{CHOP}$ has resulted in significant clinical responses. However, a subset of patients develops resistance to further treatments. The mechanism of unresponsiveness in vivo is not known. We have reported the development of rituximabresistant clones derived from B-NHL cell lines as models to investigate the mechanism of resistance. The resistant clones exhibit hyper-activated survival/anti-apoptotic pathways and no longer respond to a combination of rituximab and drugs. Recent studies reported the therapeutic efficacy in mice bearing B-cell lymphoma xenografts following treatment with the anti-CD20-hIFN $\alpha$ fusion protein. We hypothesized that the fusion protein may bypass rituximab resistance and inhibit survival signaling pathways. Treatment of the rituximab-resistant clones with anti-CD20-hIFN $\alpha$, but not with rituximab, IFN $\alpha$, or rituximab+IFN $\alpha$ resulted in significant inhibition of cell proliferation and induction of cell death. Treatment with anti-CD20-hIFN $\alpha$ sensitized the cells to apoptosis by CDDP, doxorubicin and Treanda. Treatment with anti-CD20-hIFN $\alpha$ inhibited the NF- $\mathrm{B}$ and p38 MAPK activities and induced the activation of PKC- $\delta$ and Stat-1.
\end{abstract}

Correspondence to: Dr Mario I. Vega, Oncology Research Unit, Oncology Hospital, Siglo XXI National Medical Center, IMSS, Mexico City 06720, Mexico

E-mail: marioi@unam.mx

Dr Benjamin Bonavida, Department of Microbiology, Immunology and Molecular Genetics, Jonsson Comprehensive Cancer Center and David Geffen School of Medicine, University of California at Los Angeles, Los Angeles, CA 90095, USA

E-mail: bbonavida@mednet.ucla.edu

${ }^{*}$ Contributed equally

Key words: lymphoma, rituximab-resistance, IFN- $\alpha$, anti-CD20-hIFN- $\alpha$, chemosensitivity, cytotoxicity
These effects were corroborated by the use of the inhibitors SB203580 (p38 MAPK) and Rottlerin (PKC- $\delta$ ). Treatment with SB203580 enhanced the sensitization of the resistant clone by anti-CD20-hIFN $\alpha$ to CDDP apoptosis. In contrast, treatment with Rotterin inhibited significantly the sensitization induced by anti-CD20-hIFN $\alpha$. Overall, the findings demonstrate that treatment with anti-CD20-hIFN $\alpha$ reverses resistance of B-NHL. These findings suggest the potential application of anti-CD20-hIFN $\alpha$ in combination with drugs in patients unresponsive to rituximab-containing regimens.

\section{Introduction}

Non-Hodgkin's lymphoma (NHL) is the fifth or sixth most common cancer in the US, and diffuse large B-cell lymphoma (DLBCL) is the most commonly occurring lymphoma in the Western world $(1,2)$. Currently, the standard front-line therapy for DLBCL is the combination of rituximab and chemotherapy (cyclophosphamide, doxorubicin, vincristine, and prednisone) (R-CHOP), with expected 5- and 10-year overall survival (OS) rates of 58 and $43.5 \%$, respectively (3). Rituximab is a chimeric monoclonal antibody (mAb) targeting CD20. Rituximab acts, in part, by engaging $\mathrm{Fc}$ receptors on immune effector cells, such as NK and macrophages, and induces cytotoxicity by antibody-dependent cellular cytotoxicity (ADCC). It also activates complement-dependent cytotoxicity (CDC) and rarely induces apoptosis (4). While therapeutic outcomes have improved in the post-rituximab era, there is evidence of patients exhibiting rituximab-resistance (RR). Thus, attempts to overcome RR have been a major focus of novel therapeutic developments. The mechanisms of resistances in vivo are not clear. Several mechanisms underlying RR have been postulated. These included resistance to antibody-mediated cytotoxicity mechanisms (ADCC, CDC, and induction of apoptosis), Fc-receptors polymorphisms, downregulation or loss of CD20 expression, altered antibody pharmacokinetics and altered molecular signaling pathways through CD20 (5).

We have explored the potential mechanisms of rituximab resistance by developing in vitro clones of rituximab-resistant 
(RR) variants in several B-NHL cell lines and characterized their properties. Briefly, unlike the parental wild-type, the RR clones express CD20 but no longer respond to treatments with rituximab or combination of rituximab and cytotoxic drugs. Further, the RR clones overexpressed the activity of several survival/anti-apoptotic pathways. Interference in the activity of these hyper-activated pathways reversed resistance (6). In the hope of overcoming rituximab resistance alternative therapies such as the use of HDAC or Bcl-2 inhibitors have also been demonstrated to enhance sensitization of tumor cells to rituximab (7). The efficacy of rituximab has also been shown to be augmented when used in combination with biological agents such as interferon- $\alpha-2 \mathrm{a}(\mathrm{IFN}-\alpha)$, specific interleukins, bortezomib and lenalidomide (8).

An alternative strategy for the management of patients with lymphoma has been to use biologic agents instead of chemotherapy in relapsed and refractory lymphoma patients. Clinical trials using rituximab alone or in combination with IFN- $\alpha$ have shown that T-cells are important for the survival for lymphoma patients (9). Preclinical studies have suggested a synergistic activity by the combination of IFN- $\alpha$ and rituximab and phase II clinical trials exploring the use of this combination yielded promising results $(10,11)$. Due to the good results of this randomized phase clinical II trial, the priming effect of INF- $\alpha$ on malignant B cells and immune-cells was evaluated in a large randomized phase III trial with preliminary promising results (12).

IFN- $\alpha$ is a cytokine that affects diverse biologic functions as antiviral activity, immunomodulatory action, cell differentiation, and cell survival or death, in a variety of cell types $(13,14)$. IFN- $\alpha$ has been employed for the treatment of certain tumors including hairy cell leukemia, chronic myelogenous leukemia, melanoma and renal cancer $(15,16)$. In some cases, the antitumor action of IFN- $\alpha$ has been shown to involve the induction of apoptosis through the activation of JNK via PKC- $\delta$, leading to upregulation of TRAIL and activation of Stat-1 (17).

An alternative approach to tumor immunotherapy is the development and application of fusion proteins. Fusion proteins have been employed to deliver cytokines, radioisotopes and toxins for cancer therapy (18). Recent studies have demonstrated that a fusion protein consisting of anti-CD20 antibody and IFN- $\alpha$ (anti-CD20-hIFN- $\alpha$ ) exhibited superior activity over rituximab, IFN- $\alpha$ or the combination, with significant anti-proliferative and apoptotic effects in vitro against several B-NHL cell lines. In vivo, anti-CD20-hIFN- $\alpha$ showed a significant antitumor activity against xenografts (19). Hence, we hypothesized that anti-CD20-hIFN- $\alpha$ treatment may also be effective against the RR clones.

To test the above hypothesis, the followings were investigated: i) do the RR B-NHL clones respond to antiCD20-hIFN- $\alpha$ treatment with a decrease in both cell viability and cell recovery? ii) Does the drug resistance of the RR clones reverse following treatment by the combination of chemotherapeutic drugs with anti-CD20-hIFN- $\alpha$ ? iii) Does treatment of the RR clones with anti-CD20-hIFN- $\alpha$ signal the cells and modify their survival/anti-apoptotic pathways? and iv) Does the treatment of the RR clones with inhibitors of gene products modified by anti-CD20-hIFN- $\alpha$ result in the reversal of drug resistance? The findings corroborated the above hypothesis. It was found that the RR clones responded to anti-CD20-hIFN- $\alpha$ treatment, but not to anti-CD20, hIFN $\alpha$ or combination, and treatment with anti-CD20-hIFN- $\alpha$ sensitized the drug-resistant RR clones to drug-induced apoptosis.

\section{Materials and methods}

Cell lines and reagents. The human B-NHL cell lines Ramos and 2F7 were purchased from the ATCC (Manassas, VA, USA). Clones were developed as previously reported (20). Briefly, the cells were grown in the presence of step-wise increasing concentrations of rituximab $(5-20 \mu \mathrm{g} / \mathrm{ml})$ for 10 weeks. Single cells were then isolated and subjected to three consecutive rounds of limiting dilution analyses. The cell lines were cultured as described previously (21). All cells used in this study were within 15 passages after resuscitation. The cells were checked routinely by morphology and tested for mycoplasma contamination with the CELLshipper ${ }^{\circledR}$ Mycoplasma Detection kit (Bionique ${ }^{\circledR}$ Testing Laboratories, Saranac Lake, NY, USA). Rituximab was commercially obtained. CDDP was purchased from Sigma (St. Louis, MO, USA) and was diluted in DMSO. Treanda ${ }^{\circledR}$ (bendamustine hydrochloride) was purchased from Cephalon, Inc., (Teva Pharmaceutical Industries Ltd. Frazer, PA, USA). Adriamycin ${ }^{\circledR}$ (doxorubicin) was purchased from Sun Pharma Global FZE. The PE-labeled anti-active caspase-3 antibody and the corresponding IgG1 isotype controls were obtained from BD Pharmingen (San Diego, CA, USA). The following antibodies were obtained from Santa Cruz Biotechnology (Santa Cruz, CA, USA) and were directed against $\mathrm{Bcl}_{-\mathrm{xL}}$, Bcl-6, p65, phospho-p65 (Ser 536), p38, phospho-p38 (Thr180-Tyr182), Bax, PKC- $\delta$, phospho-PKC- $\delta$ (Thr 505), Stat-1, phospho-Stat-1 (Tyr701 and Ser727), and phospho-JNK (Thr183/Tyr185). The genetically engineered anti-CD20-hIFN $\alpha$ was developed as described by Xuan et al (19) and kindly provided by Dr Sherie L. Morrison, UCLA. Human IgG (Sigma) was used as control. IFN- $\alpha 2$ a was purchased from Sigma-Aldrich Co. (USA), the PKC- $\delta$ inhibitor rottlerin was obtained from Sigma-Aldrich Co.. The p38 Map kinase inhibitor SB203580 was purchased from Cell Signaling Technology, Inc. (USA).

Viability assay. Cell viability was assessed by either the trypan blue dye exclusion assay by microscopy or by the XTT dye absorbance according to the manufacturer's instructions (Roche Diagnostic GmbH, Nonnenwald, Germany) as previously described (21). The viability of the untreated cells was set at $100 \%$ and total cell recovery was recorded. Each experimental condition was performed in triplicate and the SD was calculated.

Apoptosis determination. Apoptosis was assessed in tumor cells by flow cytometry for activated caspase- 3 as previously described (21). Briefly, B-NHL cell cultures were preincubated with various concentrations of the anti-CD20-hIFN $\alpha$ fusion protein $(30,50$ or $100 \mathrm{pM})$, or rituximab, rhIFN- $\alpha$ (equivalent range of concentrations) or combination of rituximab and rhIFN- $\alpha$ for $18 \mathrm{~h}$ and CDDP, Treanda or doxorubicin (10, 5 and $5 \mu \mathrm{g} / \mathrm{ml}$ ), respectively, were added for an additional $18 \mathrm{~h}$ at at $37^{\circ} \mathrm{C}$. The cells were stained intracellularly for activated caspase- 3 and the samples were analyzed by flow cytometry. 
Population data were acquired on a Flow Centre EPICSR XL-MCL (Coulter, Co.) with System II software and the percentage of positive cells was recorded.

Western blot analysis for protein expression. B-NHL cell lines were incubated with or without $100 \mathrm{pM}$ of anti-CD20hIFN $\alpha$ or rituximab at $37^{\circ} \mathrm{C}$ for $18 \mathrm{~h}$. Western blot analysis was performed as previously described (21). Briefly, cell extracts for protein analysis were prepared by lysing $2 \times 10^{6}$ cells on ice with cold $200 \mu \mathrm{l}$ of radioimmunoprecipitation assay buffer [1\% NP40, 0.1\% SDS, 0.5\% deoxycholic acid, complete protease inhibitor cocktail tablets (Roche Diagnostic Co.), and $1 \mathrm{X}$ PBS]. Lysates were transferred to microcentrifuge tubes and sonicated in the Sonicator, model W-220F (HeatSystem Ultrasonic, Inc.) for $10 \mathrm{sec}$. Lysates were centrifuged at $12,000 \mathrm{x} \mathrm{g}$ at $4^{\circ} \mathrm{C}$ for $5 \mathrm{~min}$. Protein concentration was quantified using the Bio-Rad protein assay (Bio-Rad Laboratories). Gel loading buffer Bio-Rad (Bio-Rad Laboratories) was added to the cell lysates at a 1:1 volume. Samples were boiled for 5 min and were separated on $12 \%$ SDS-polyacrylamide minigels and transferred to a nitrocellulose membrane Hybond enhanced chemiluminescence (Amersham Pharmacia Biotech) in Trans-Blot SD semidry Transfer Cell System (Bio-Rad).

Statistical analysis. All results were expressed as the mean \pm SD of data obtained from three triplicate, independent and separate experiments. The statistical significance of differences between group means was determined using one-way ANOVA to compare variance. Significant differences were considered for probabilities $<5 \%(\mathrm{p}<0.05)$.

\section{Results}

Effects of anti-CD20-hIFN- $\alpha$ treatment on the proliferation and viability of various $B-N H L$ cell lines. The $2 \mathrm{~F} 7$ and Ramos B-NHL cell lines and their rituximab-resistant variants, 2F7R and Ramos $\mathrm{R}$, were treated with different concentrations of anti-CD20-hIFN- $\alpha$ and equimolar concentrations of rituximab (30, 50 and 100 pM), IFN- $\alpha$, or rituximab+IFN- $\alpha$ or for $18 \mathrm{~h}$ and examined for cell recovery, cell viability and apoptosis. Treatment with anti-CD20-hIFN- $\alpha$, in contrast to treatment with rituximab, IFN- $\alpha$, or rituximab+IFN- $\alpha$, resulted in significant inhibition of cell recovery in 2F7 at a concentration $>50 \mathrm{pM}$. With $2 \mathrm{~F} 7 \mathrm{R}$, there was a significant inhibition of cell recovery at the concentration of $30 \mathrm{pM}$ and an augmented inhibition at 50 and 100 pM of anti-CD20-hIFN- $\alpha$ (Fig. 1A, upper right panel). With Ramos cells, there was inhibition at $>50 \mathrm{pM}$ of anti-CD20-hIFN- $\alpha$ treatment. Likewise, there was significant inhibition of Ramos R by anti-CD20-hIFN- $\alpha$ at concentrations $\geq 50 \mathrm{pM}$ (Fig. 1A, lower panels). These findings demonstrate that, in contrast to treatments with rituximab, IFN- $\alpha$ or rituximab+IFN- $\alpha$, treatment with anti-CD20-hIFN $\alpha$ inhibited significantly the cell recovery in both the $2 \mathrm{~F} 7 \mathrm{R}$ and Ramos R cell lines.

The viability of the cell lines treated with the above agents was determined microscopically by trypan blue dye exclusion. In contrast to the treatments with rituximab, IFN- $\alpha$ or rituximab+IFN- $\alpha$, treatment with anti-CD20-hIFN- $\alpha$ induced significant cytotoxicity in all the cell lines (2F7, 2F7R, Ramos, and Ramos R) at concentrations $\geq 50 \mathrm{pM}$ (Fig. 1B). These findings suggested that the inhibition of the cell recovery shown in Fig. 1A was the result, in part, of cell loss induced by anti-CD20-hIFN- $\alpha$.

The cytotoxic activity exhibited by anti-CD20-hIFN- $\alpha$ above in Fig. 1B by dye exclusion was also examined for apoptotic activity as assessed by the activation of procaspase- 3 as described in Materials and methods. The findings showed that treatment with anti-CD20-hIFN- $\alpha$, but not with rituximab, IFN- $\alpha$ or rituximab+IFN- $\alpha$, induced apoptosis in all four of the cell lines tested (Fig. 1C). With 2F7, there was significant apoptosis induction following treatment with anti-CD20hIFN $\alpha$ at $50 \mathrm{pM}$, whereas, in $2 \mathrm{~F} 7 \mathrm{R}$, there was significant apoptosis at $\geq 30 \mathrm{pM}$. Also, a significant number of cells undergoing apoptosis was recorded in both Ramos and Ramos $\mathrm{R}$ cell clones treated with anti-CD20-hIFN- $\alpha$ at $\geq 30 \mathrm{pM}$.

Overall, the above findings demonstrated clearly that the response of RR clones to treatment with anti-CD20-hIFN- $\alpha$ could not be mimicked by the treatment with single agents or the combination of anti-CD20 and hIFN- $\alpha$. Further, the findings also supported the contention that treatments with anti-CD20-hIFN- $\alpha$ signalled and triggered the RR cells leading to cell death and apoptosis. This cell signaling in the RR clones was conditioned on the fusion protein and was not induced by the combination of rituximab and hIFN- $\alpha$.

Chemosensitization of $2 F 7 R$ and Ramos $R$ cells following treatment with anti-CD20-hIFN- $\alpha$ and chemotherapeutic drugs. Previous reports have demonstrated that drug resistance of the wild-type B-NHL cell lines, but not the rituximab-resistant variants, can be reversed following treatment with rituximab $(22,23)$. These findings are corroborated here for the 2F7, 2F7R, Ramos and Ramos R B-NHL cell lines treated with rituximab and CDDP (Fig. 2A, upper and bottom left panels). Noteworthy, treatment with anti-CD20hIFN- $\alpha$ and CDDP, in contrast to rituximab+CDDP, resulted in significant induction of apoptosis in 2F7R and Ramos $\mathrm{R}$ at anti-CD20-hIFN- $\alpha$ concentrations of $\geq 30 \mathrm{pM}$ (Fig. $2 \mathrm{~A}$ ). The chemosensitization-induced apoptosis by anti-CD20-hIFN- $\alpha$ was detected at 24, 48 and $72 \mathrm{~h}$ following treatment (Fig. 2B). These findings suggested that signaling by anti-CD20-hIFN- $\alpha$ on 2F7R and Ramos R must have altered the anti-apoptotic pathways and thus, resulting in the sensitization of the cells to CDDP apoptosis. Similar sensitizations had been observed by the combination treatment of rituximab+CDDP on the wildtype Ramos and 2F7 cell lines.

In addition to CDDP, we also examined the sensitizing activity of the anti-CD20-hIFN- $\alpha$ treatment on Treandainduced apoptosis. Treatment of the wild-type cell lines 2F7 and Ramos with rituximab+Treanda resulted in significant apoptosis as compared to treatment with single agents (Fig. 2C, left panels). The combination of rituximab+Treanda did not result in increased apoptosis for either the 2F7R or Ramos $\mathrm{R}$ cell lines (Fig. 2C, right panels). In contrast, treatment with anti-CD20-hIFN- $\alpha$ in combination with Treanda resulted in significant apoptosis in both the 2F7R and Ramos R cell lines (Fig. 2C, right panels). Similar findings were obtained with the combination of anti-CD20-hIFN- $\alpha$ and doxorubicin (Fig. 2D). Thus, treatment with anti-CD20-hIFN- $\alpha$ sensitized the RR cell lines, findings that could not be achieved by the combination of rituximab and chemotherapeutic agents. 


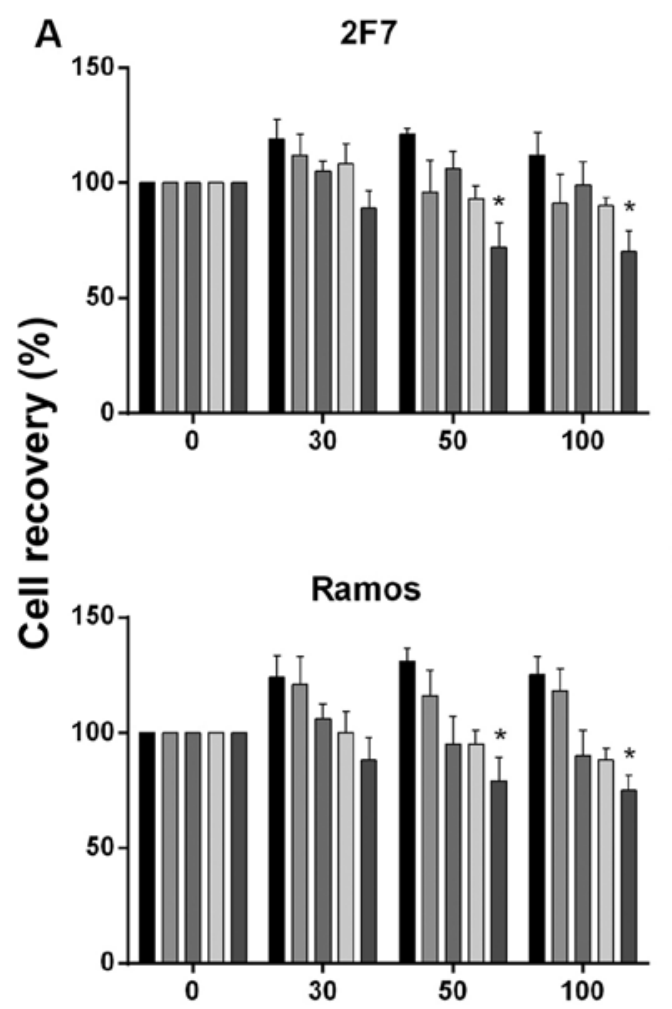

\section{Protein concentration (pM)}

B

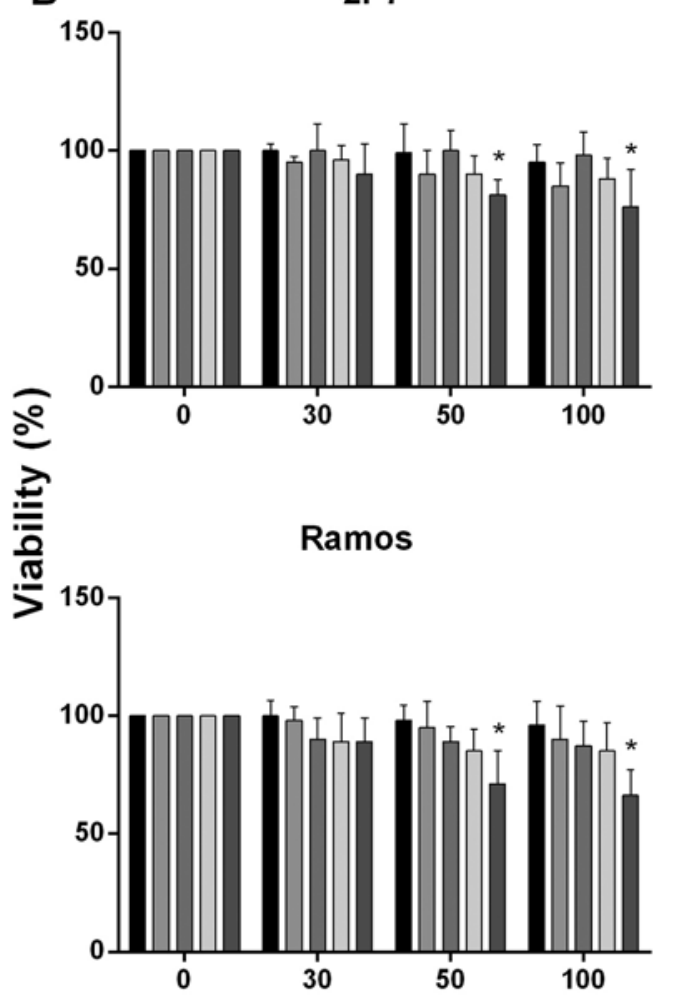

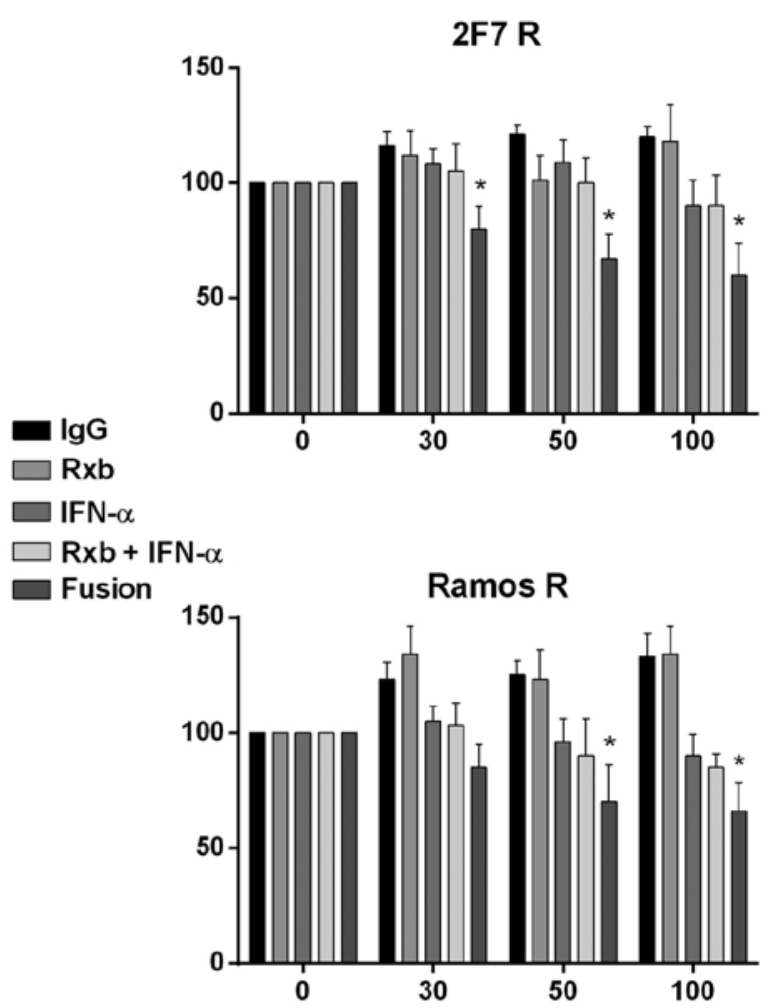

Protein concentration (pM)

Figure 1. Anti-CD20-hIFN- $\alpha$ induces inhibition of cell recovery and viability and induction of apoptosis in rituximab-resistant (R) B-NHL cell lines. (A) The B-NHL cell lines 2F7, 2F7R, Ramos and Ramos R were treated with various concentrations of anti-CD20-hIFN- $\alpha$ (30, 50 or $100 \mathrm{pM})$ or equimolar concentrations of rituximab, rhIFN- $\alpha$ or the combination and incubated for $18 \mathrm{~h}$. The total cell recovery was determined by trypan blue dye-exclusion. The B-NHL cell lines treated with normal $\mathrm{IgG}$ represent $100 \%$ cells recovered. The data represent the mean \pm SD from triplicate values, ${ }^{*} \mathrm{p}<0.05$. (B) The B-NHL cell lines $2 \mathrm{~F} 7$, 2F7R, Ramos and Ramos R were treated with various concentrations of anti-CD20-hIFN- $\alpha$ (30, 50 or $100 \mathrm{pM})$ or equimolar concentrations of rituximab, rhIFN- $\alpha$ or the combination and incubated for $18 \mathrm{~h}$ and cell viability was determined by the XTT assay. B-NHL cell lines treated with normal IgG represent $100 \%$ cells recovered. The data represent the mean \pm SD from triplicate values, ${ }^{*} \mathrm{p}<0.05$. 

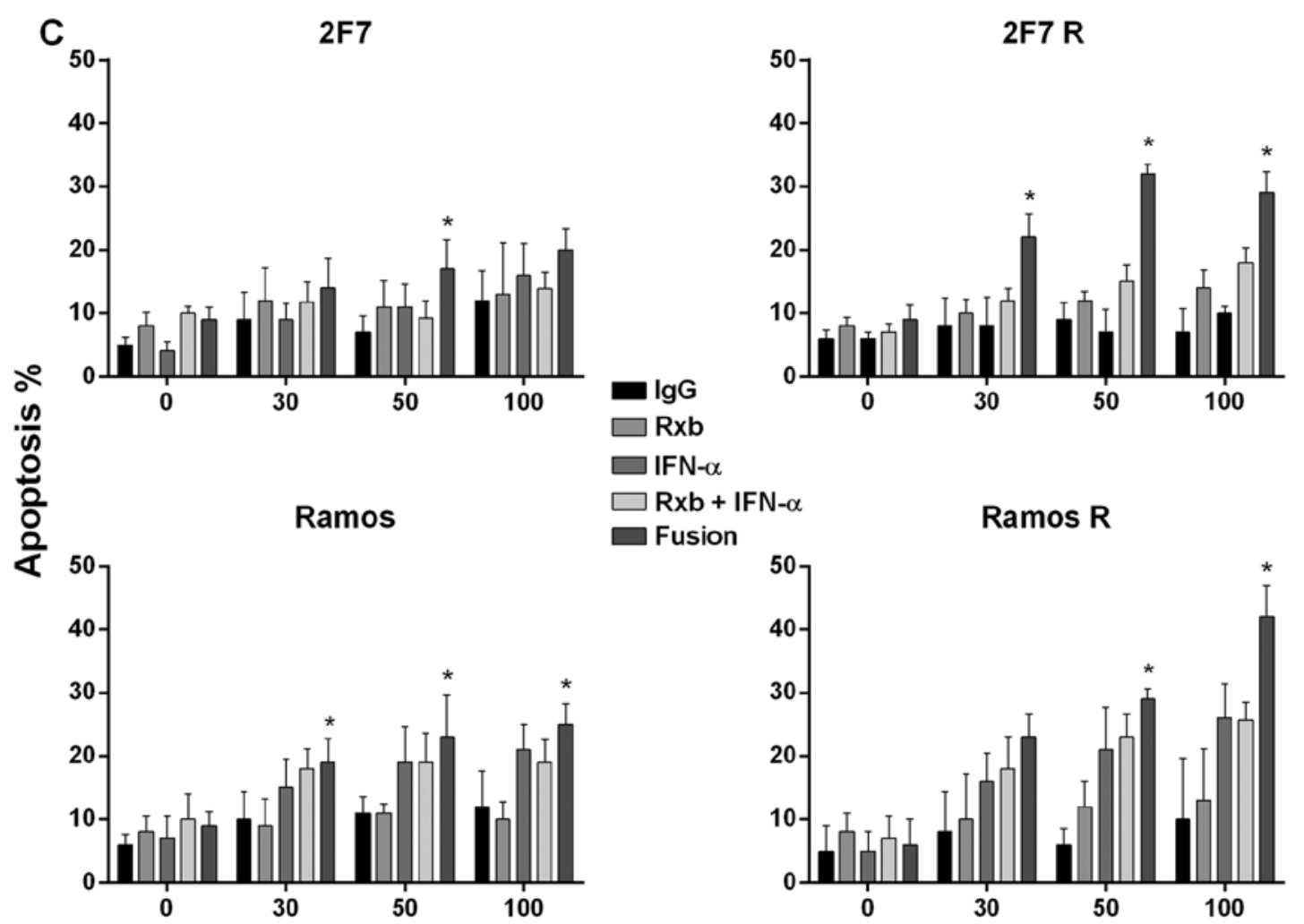

\section{Protein concentration (pM)}

Figure 1. Continued. (C) The B-NHL cell lines 2F7, 2F7 R, Ramos and Ramos R were treated with various concentrations of anti-CD20-hIFN- $\alpha$ (30, 50 or $100 \mathrm{pM}$ ) or equimolar concentrations of rituximab, rhIFN- $\alpha$ or the combination and incubated for $18 \mathrm{~h}$ and apoptosis was determined as assessed by activated caspase- 3 , as described in Materials and methods. The data represent the mean \pm SD from triplicate values, ${ }^{*} \mathrm{p}<0.05$.

Cell signaling mediated by anti-CD20-hIFN- $\alpha$ following treatment of the Ramos $R$ and $2 F 7 R$ cell lines. Previously, we have shown that treatment of wild-type B-NHL cell lines with rituximab resulted in the inhibition of several survival and anti-apoptotic pathways (23). These modifications were responsible, in part, for the chemosensitization of the cells to drug-induced apoptosis. Based on the present findings that treatment of the resistant variants with anti-CD20-hIFN- $\alpha$ resulted in the inhibition of cell recovery, the induction of cell apoptosis and the sensitization to drugs, we deduced that treatment with anti-CD20-hIFN- $\alpha$ must have altered cell survival pathways. We analyzed by western blotting several proteins involved in survival following treatment with either rituximab or anti-CD20-hIFN- $\alpha$. Treatment of Ramos with either rituximab or anti-CD20-hIFN- $\alpha$ resulted in similar inhibition of p-p38, p-p65 and $\mathrm{Bcl}_{-\mathrm{XL}}$ (Fig. 3A). In addition, treatment with anti-CD20-hIFN- $\alpha$ resulted in the upregulation of Bax. As expected, consistent with previous studies, treatment of Ramos $\mathrm{R}$ with rituximab did not have any effect on the expression of these proteins. In marked contrast, treatment of Ramos R with anti-CD20-hIFN- $\alpha$ resulted in significant inhibition of p-p38, p-p65, Bcl- ${ }_{\mathrm{xL}}$ and the induction of Bax (Fig. 3A). These findings demonstrated that treatment with anti-CD20-hIFN- $\alpha$ signaled the Ramos R cells similarly to the signaling observed following treatment of the wild-type Ramos cells with rituximab.
In addition to the mentioned gene products, we also examined other signaling pathways that may be induced by IFN- $\alpha$ and that may have contributed to the signaling by antiCD20-hIFN- $\alpha$. Treatment of Ramos with anti-CD20-hIFN- $\alpha$ resulted in the activation of PKC- $\delta(p-P K C-\delta)$ and Stat-1 but had no effect on Bcl-6, and p-JNK (Fig. 3B). However, treatment of Ramos R with anti-CD20-hIFN- $\alpha$, but not with rituximab, resulted in significant overexpression of $\mathrm{p}-\mathrm{PKC}-\delta$ and p-Stat-1 (Fig. 3B) and inhibition of Bcl-6 expression: there was no effect on p-JNK. Treatment of Ramos or Ramos R with hIFN- $\alpha$ induced p-PKC- $\delta$ (Fig. 3C), suggesting that hIFN- $\alpha$ in the fusion protein contributed to the activation of p-PKC- $\delta$.

The above findings demonstrated that treatment of the Ramos R cell line with anti-CD20-hIFN $\alpha$ impacted pathways already observed following treatment of wild-type Ramos with rituximab alone as well as by IFN- $\alpha$ alone. Thus, rituximab and IFN- $\alpha$ in the anti-CD20-hIFN- $\alpha$ fusion protein each contributed to the signaling observed in Ramos R.

Roles of the p-p38 and PKC- $\delta$ by anti-CD20-hIFN- $\alpha$ in chemosensitization to CDDP and doxorubicin

a) Effect of the PKC- $\delta$ inhibitor Rotterin on the sensitization of $2 F 7 R$ and Ramos $R$ cell lines by anti-CD20-hIFN- $\alpha$ to $C D D P$-induced apoptosis. Since treatment of Ramos $\mathrm{R}$ with anti-CD20-hIFN- $\alpha$ induced p-pKC- $\delta$ (Fig. 3B) we examined the role of $\mathrm{p}-\mathrm{pKC}-\delta$ induction on chemosensitization by 
A

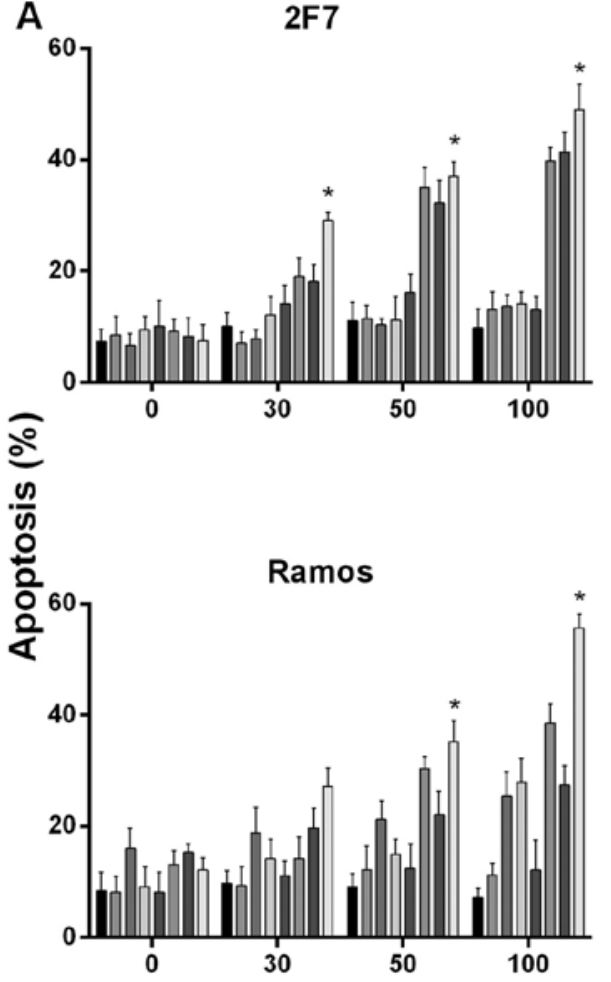

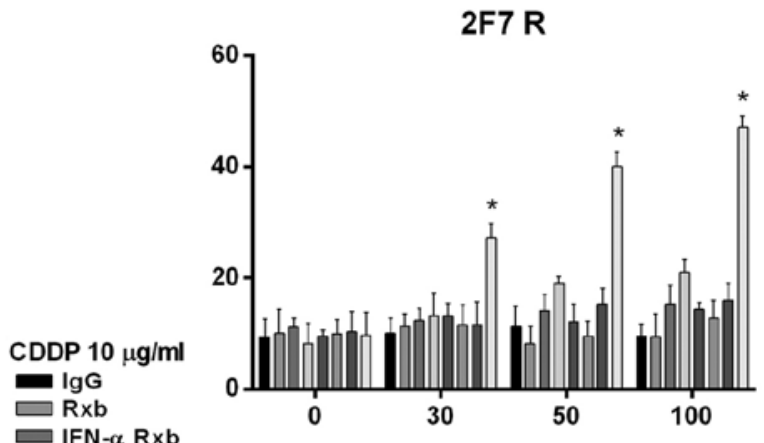

$\square$ IFN- $\alpha$ Rxb $\square$ Fusion $\operatorname{lgG}+$ CDDP IFN $-\alpha$ Rxb + CDDP $\square$ Fusion + CDDP

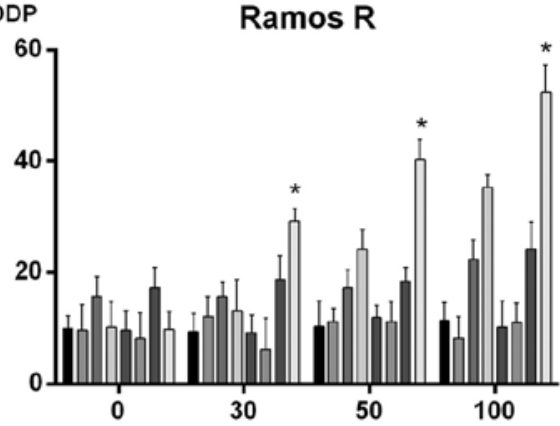

Protein concentration (pM)
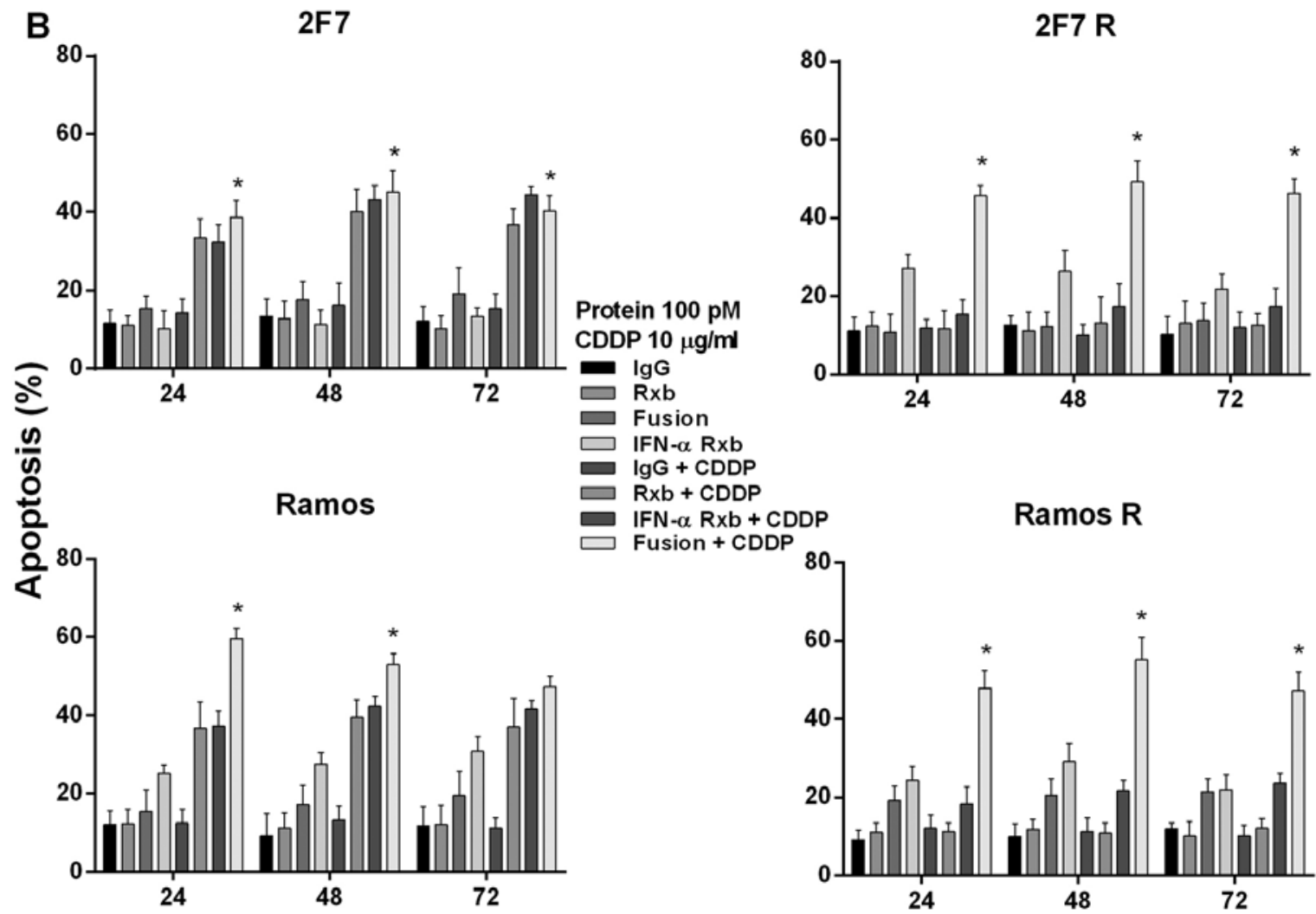

Ramos R

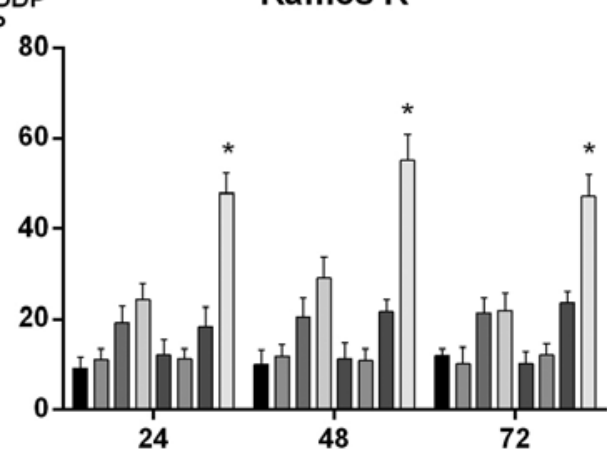

Time (h)

Figure 2. Anti-CD20-hIFN- $\alpha$ sensitizes rituximab-resistant B-NHL cell lines to apoptosis by chemotherapy. (A) The indicated B-NHL cell lines cells were treated with various concentrations of anti-CD20-hIFN- $\alpha(30,50$ or $100 \mathrm{pM})$ or equivalent concentrations of rituximab or rhIFN- $\alpha$ for $18 \mathrm{~h}$ and then treated with CDDP $(10 \mu \mathrm{g} / \mathrm{ml})$ for an additional $18 \mathrm{~h}$. Apoptosis was determined as described in Materials and methods. The data represent the mean \pm SD from three independent experiments, ${ }^{*}$ p $<0.05$. (B) Treatment of rituximab-resistant B-NHL cell lines with anti-CD20-hIFN- $\alpha$ and CDDP for various times. The indicated B-NHL cell lines were treated with anti-CD20-hIFN- $\alpha(100 \mathrm{pM})$ or equivalent concentrations of rituximab, rhIFN- $\alpha$ or the combination for 24,48 or $72 \mathrm{~h}$ and then treated with CDDP $(10 \mu \mathrm{g} / \mathrm{ml})$ for an additional $18 \mathrm{~h}$. Apoptosis was determined as described. The data represent the mean \pm SD from three values, ${ }^{\mathrm{p}}<0.05$. 
C

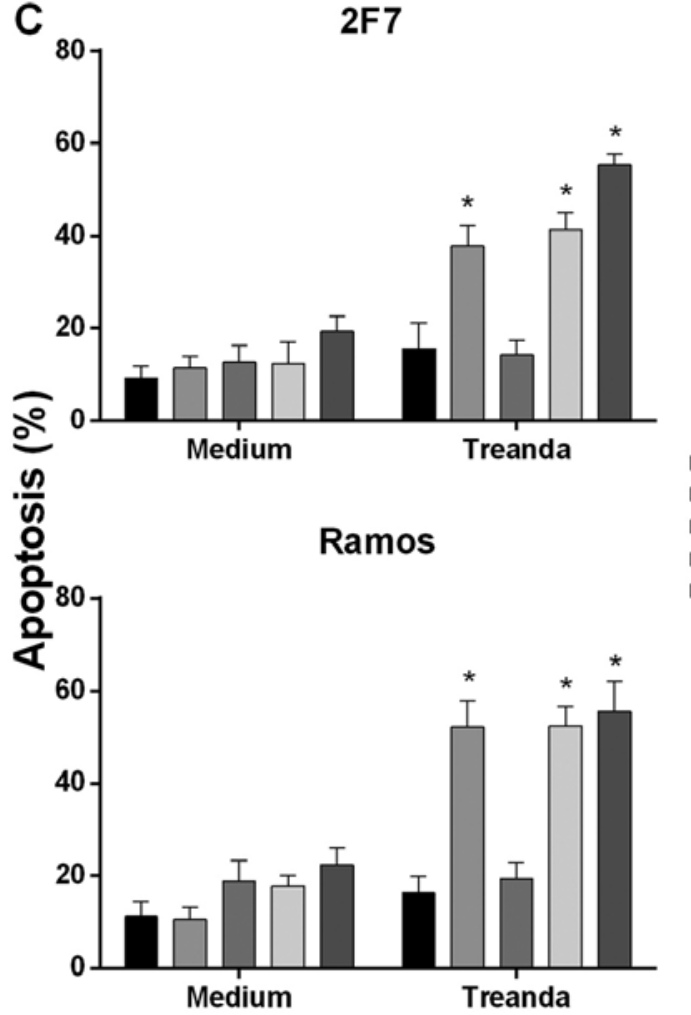

2F7 R

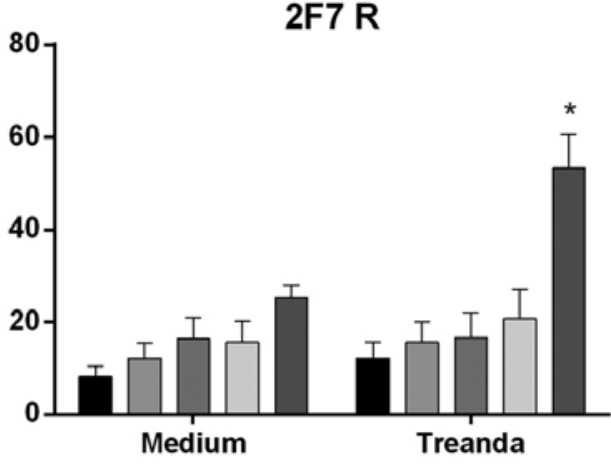

Ramos R

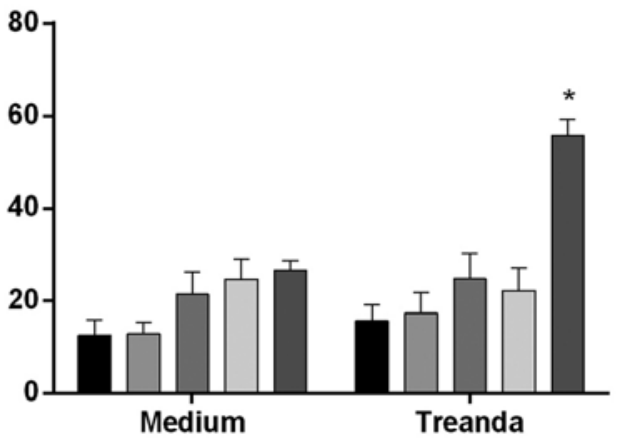

Protein concentration $100 \mathrm{pM}$
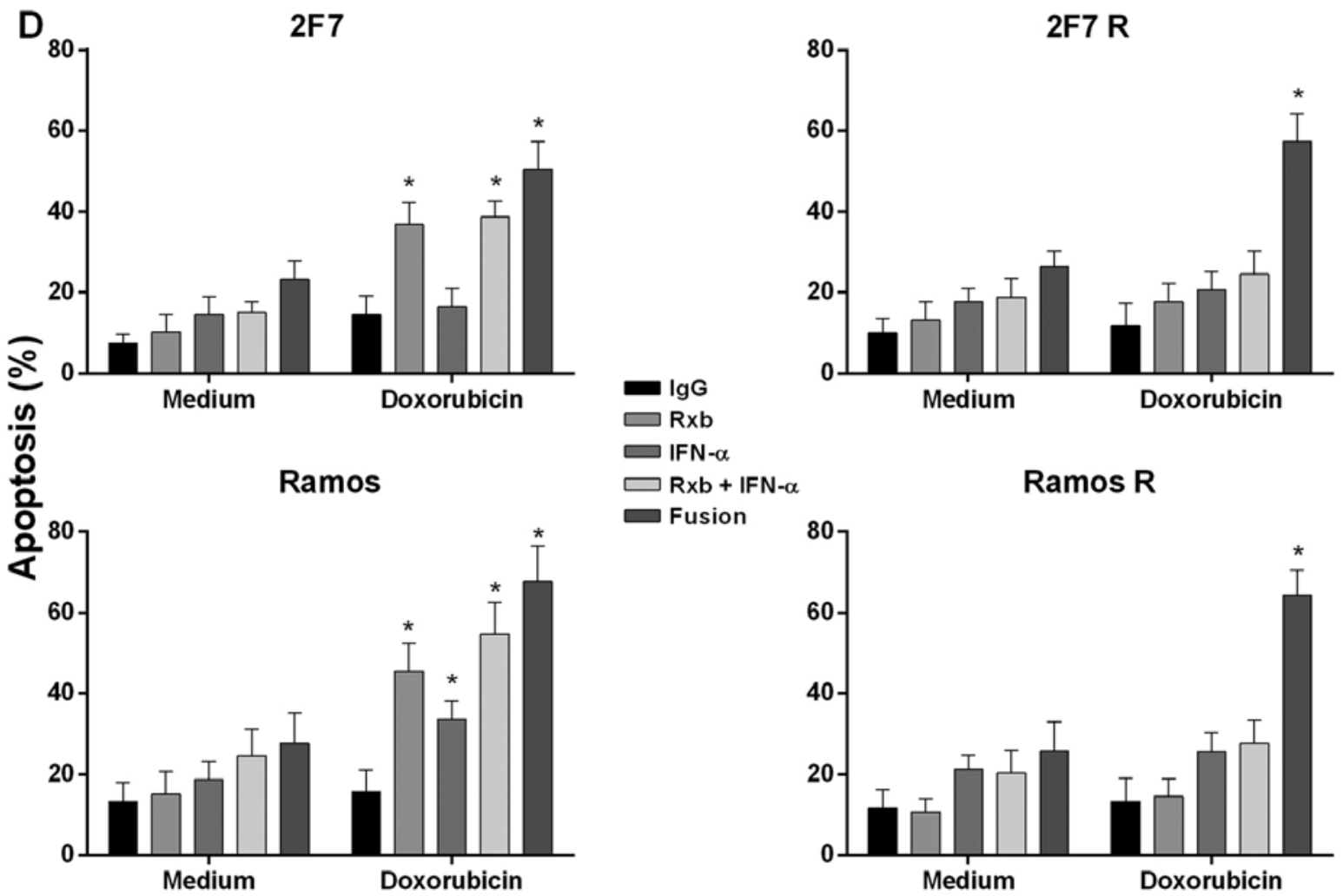

Protein concentration 100 pM

Figure 2. Continued. (C) B-NHL cell lines were treated with anti-CD20-hIFN- $\alpha$ (100 pM) or equivalent concentrations of rituximab, rhIFN- $\alpha$ or the combination for $18 \mathrm{~h}$ and then treated with Treanda $(5 \mu \mathrm{g} / \mathrm{ml})$ for an additional $18 \mathrm{~h}$ and apoptosis was determined. The data represent the mean $\pm \mathrm{SD}$ from three values, ${ }^{*} \mathrm{p}<0.05$. (D) B-NHL cell lines were treated with anti-CD20-hIFN- $\alpha$ (100 pM) or equivalent concentrations of rituximab, rhIFN- $\alpha$ or the combination for $18 \mathrm{~h}$ and then treated with doxorubicin $(5 \mu \mathrm{g} / \mathrm{ml})$ for an additional $18 \mathrm{~h}$. Apoptosis was determined as described. The data represent the mean \pm SD from three values, ${ }^{*} \mathrm{p}<0.05$. 

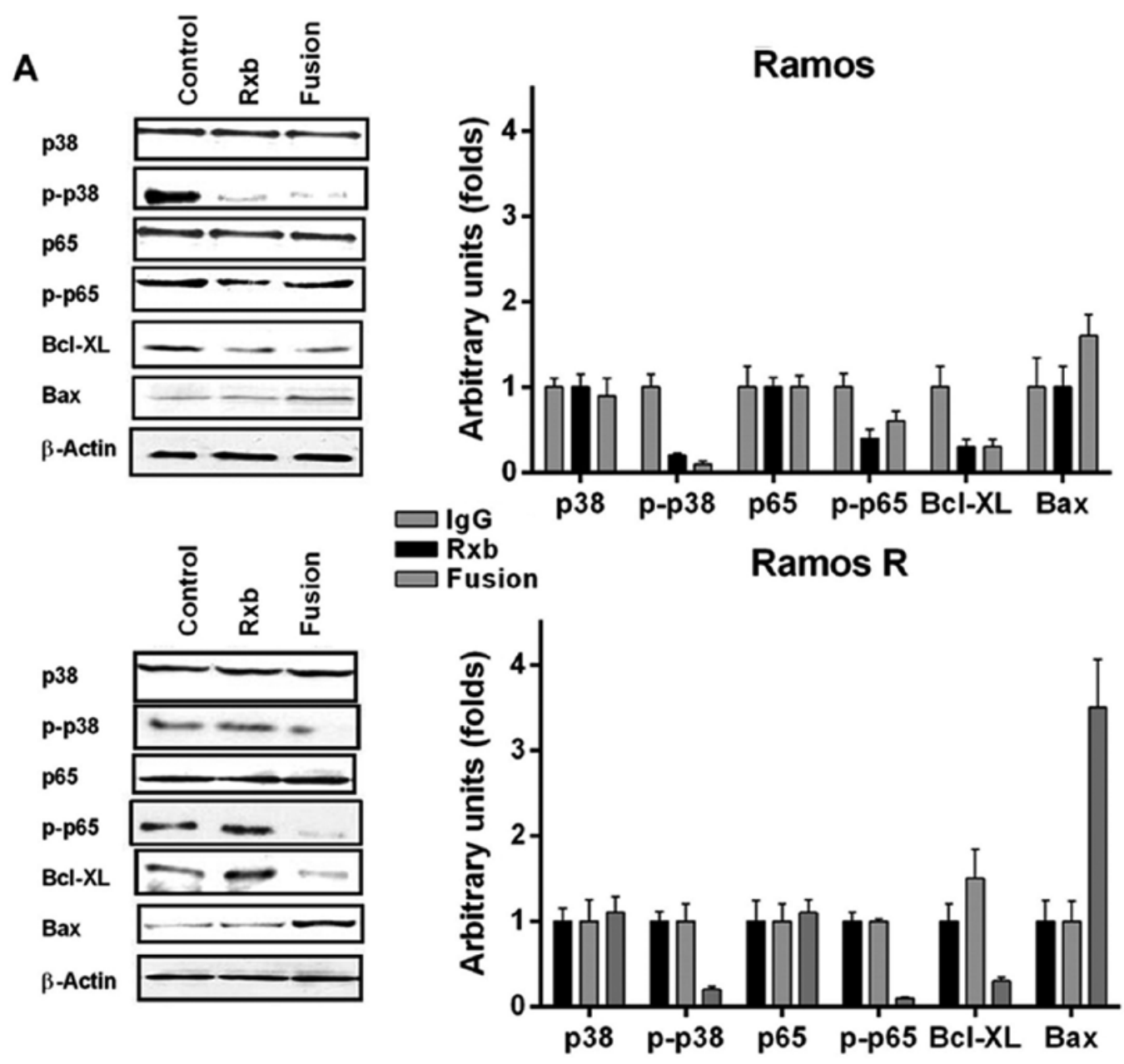

B
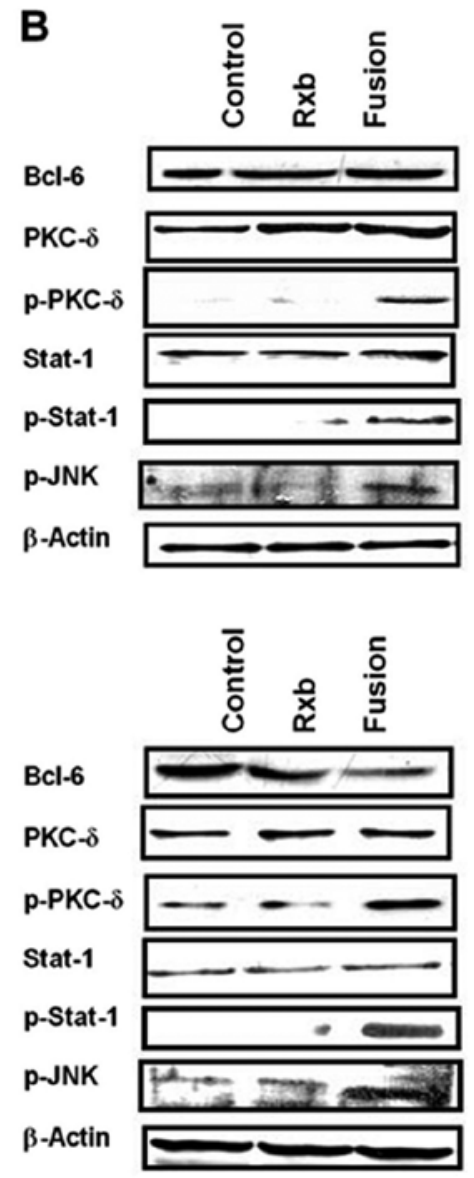

Ramos

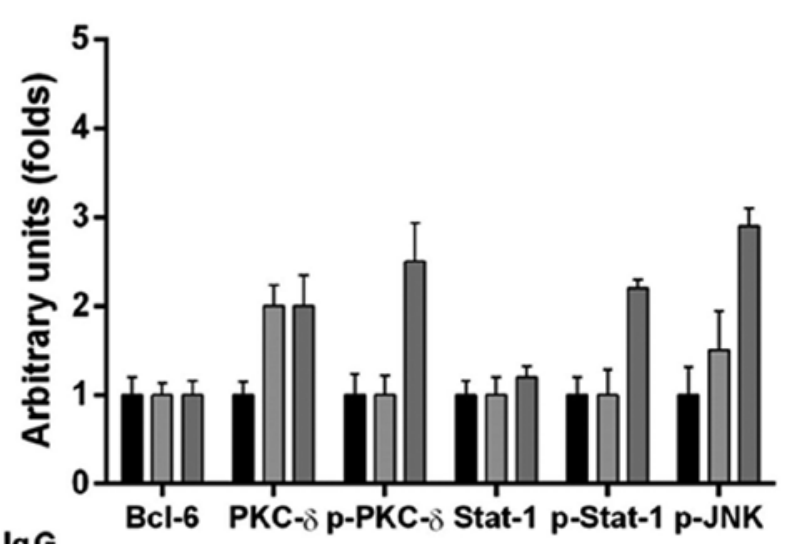

- $\lg \mathrm{G}$

$\square$ Rxb

שFusion Ramos R

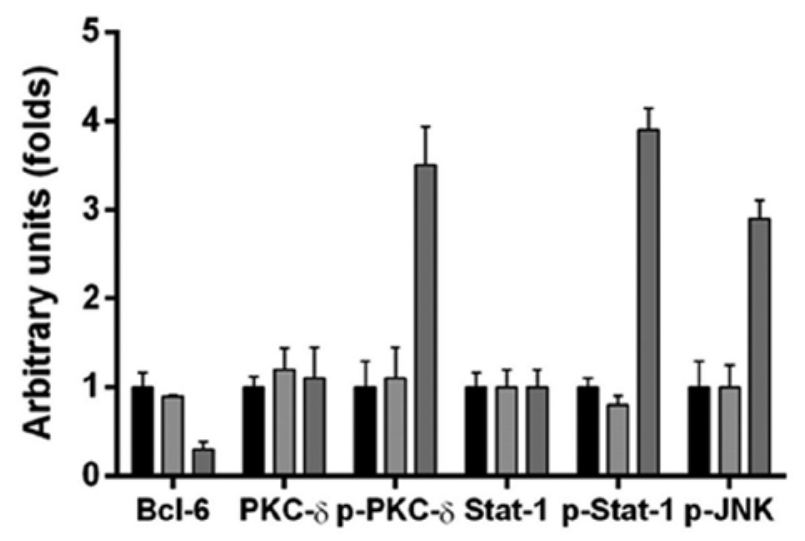




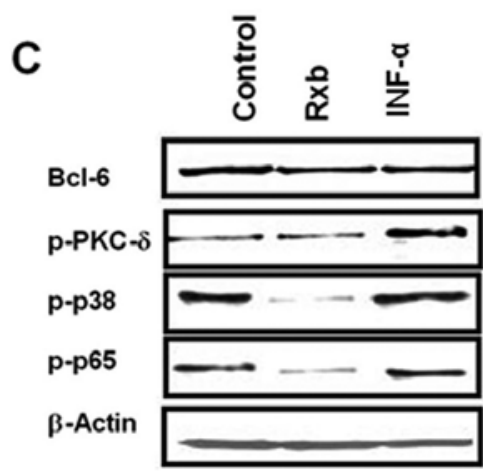

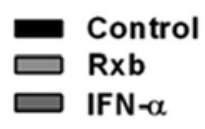

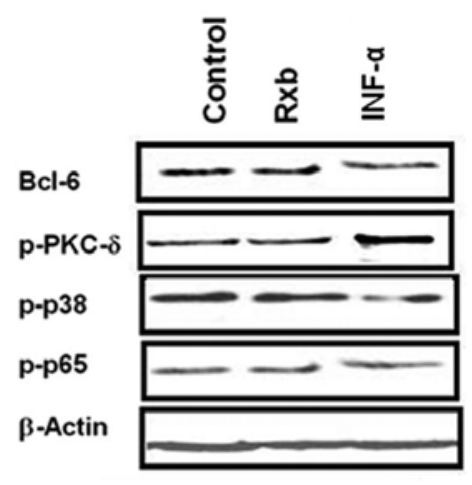

Ramos R
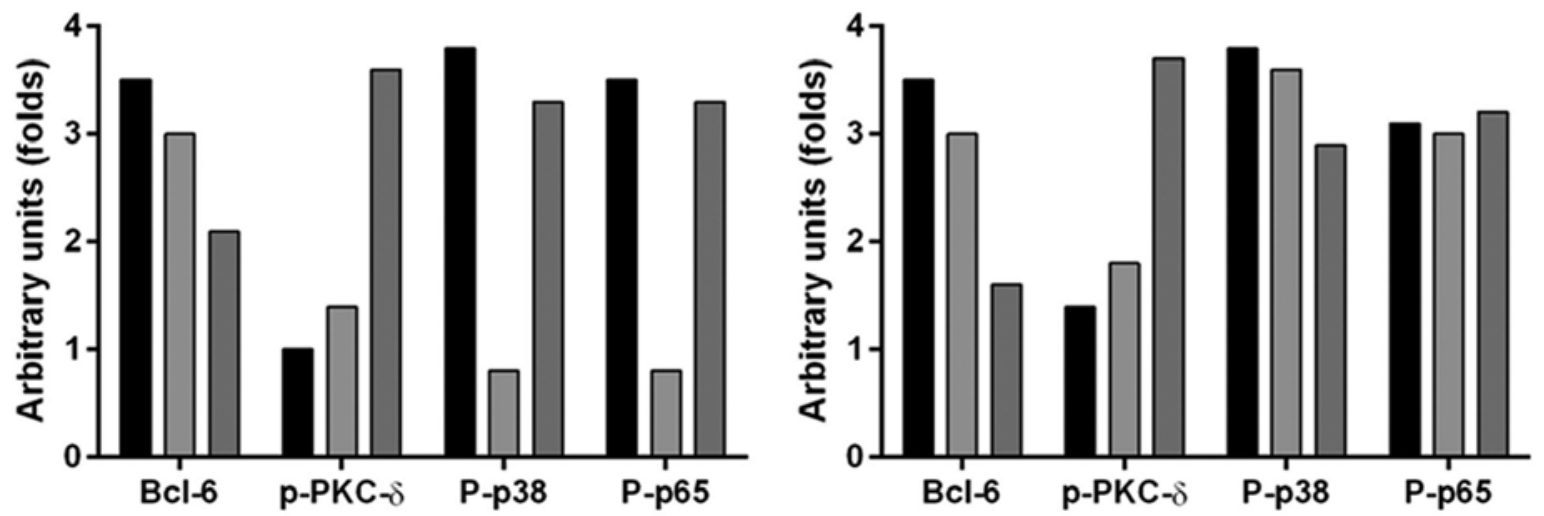

Figure 3. Treatment of rituximab-resistant B-NHL cells with anti-CD20-hIFN- $\alpha$ inhibits the activities of NF- $\kappa$ B, p38 MAPK and IFN- $\alpha$. (A) The B-NHL cell lines Ramos and Ramos R were treated with anti-CD20-hIFN- $\alpha$ (100 pM) for $18 \mathrm{~h}$ and total cell lysates were prepared and p38, p-p38, p65, p-p65 Bcl- ${ }_{\mathrm{XL}}$ and Bax proteins levels were determined by western blotting. $\beta$-actin was used as a loading control (left panel). Densitometry is presented in the right panel. (B) The B-NHL cell lines Ramos and Ramos R both treated and not, with anti-CD20-hIFN- $\alpha$ (100 pM) for $6 \mathrm{~h}$ were analyzed by western blotting for Bcl-6, PKC- $\delta$, p-PKC- $\delta$, Stat-1, p-Stat-1 and p-JNK. $\beta$-actin was used as a loading control (right panel). Densitometry is presented on the right panel. (C) Ramos and Ramos $\mathrm{R}$ were treated with rituximab or hIFN- $\alpha$ for $24 \mathrm{~h}$ and lysates were analyzed by western blotting for the expression of gene products compared to untreated controls (top images). The western blots were also analyzed by densitometry.

anti-CD20-hIFN- $\alpha$. Treatment with the PKC inhibitor rottlerin significantly inhibited the chemosensitization induced by anti-CD20-hIFN- $\alpha$ in 2F7 ( $<<0.005)$, Ramos ( $<<0.001)$, and Ramos $R(p<0.001)$ (Fig. 4A). PKC- $\delta$ is activated by IFN- $\alpha$ and there was also significant inhibition by any combination containing IFN- $\alpha$. These findings suggest the participation of IFN- $\alpha$ in anti-CD20-hIFN $\alpha$ induced chemosensitization of Ramos R cells.

b) Effect of p38 MAPK inhibition by anti-CD20-hIFN- $\alpha$ in chemosensitization. We have reported that treatment of B-NHL cells with rituximab inhibited p-p38 MAPK activity and sensitized the cells to drug apoptosis (24). Treatment of Ramos R with anti-CD20-hIFN- $\alpha$, but not with rituximab alone, inhibited p-p38 MAPK (Fig. 3A). Thus, we examined the role of anti-CD20-hIFN $\alpha$-induced inhibition of p-p38 MAPK in chemosensitization of $2 \mathrm{~F} 7 \mathrm{R}$ and Ramos $\mathrm{R}$ to doxorubicin-induced apoptosis. Treatment with the p-p38 MAPK inhibitor SB203580 was found to significantly augment the apoptosis induced by the combination of anti-CD20-hIFN- $\alpha$ and doxorubicin in all four cell lines (Fig. 4B). There was also augmentation of apoptosis by doxorubicin alone and doxorubicin $+\mathrm{IFN}-\alpha+$ rituximab. The augmented apoptosis by treatment with anti-CD20-hIFN- $\alpha$ and doxorubicin suggested that it is regulated, in part, by p-p38 MAPK and that inhibition p-p38 MAPK by anti-CD20-hIFN $\alpha$ in 2F7 R and Ramos R participated in the chemosensitization observed.

\section{Discussion}

The present standard therapy for B-NHL is anti-CD20 mAb, rituximab, plus CHOP. Although it has been shown that the combination treatment with chemotherapy and rituximab improved the remissions and the overall survival in indolent B cell lymphomas (25), the majority of patients remains incurable and new therapeutic approaches are needed. The present study reports, for the first time, the novel finding demonstrating that treatment by anti-CD20-hIFN- $\alpha$ of rituximab-resistant (RR) B-NHL clones results in the inhibition of cell proliferation, induction of apoptosis and sensitization to drug-induced apoptosis. These findings are reminiscent of our previous studies that demonstrated that intracellular inhibitors of survival pathways sensitized the RR B-NHL clones to apoptosis by various chemotherapeutic drugs. The observed response of the RR clones to anti-CD20-hIFN- $\alpha$ was specific to the fusion protein as neither anti-CD20, hIFN- $\alpha$ nor the combination was 
A

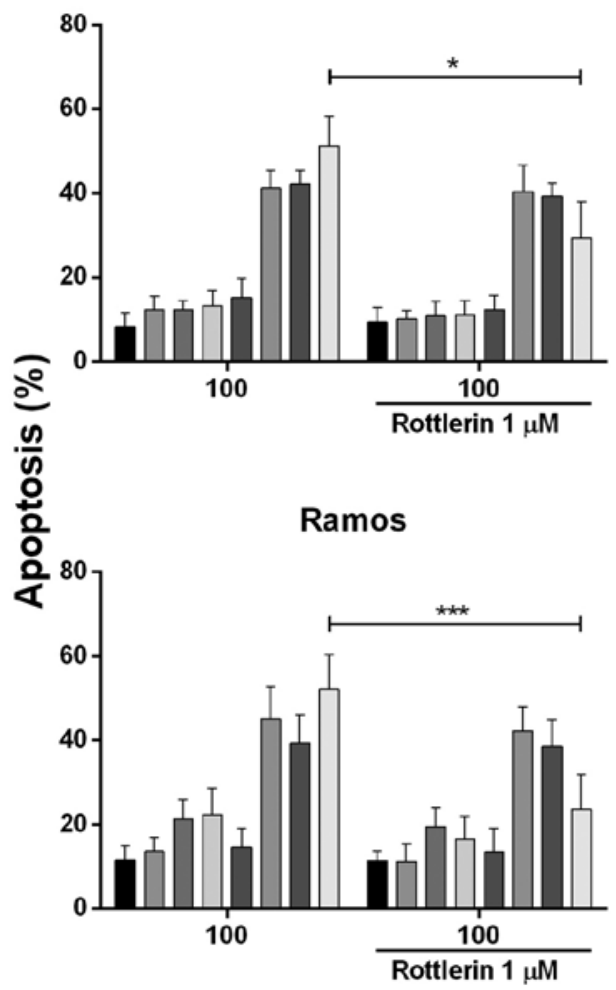

2F7 R

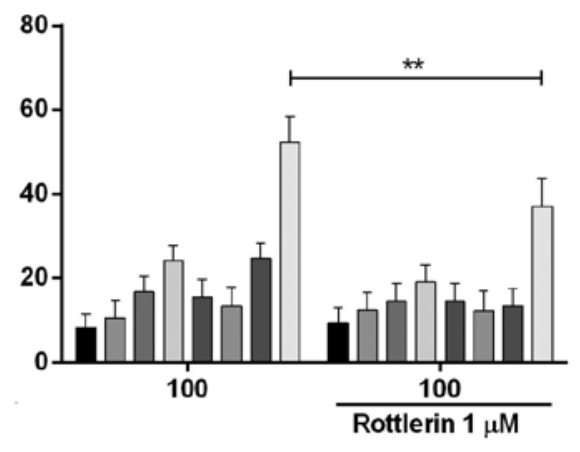

Ramos R

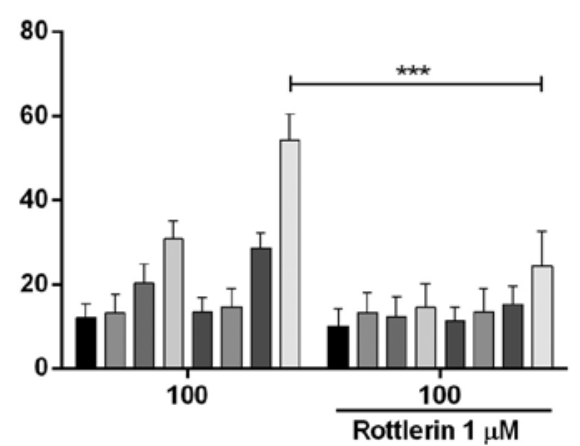

Protein concentration (pM)

B

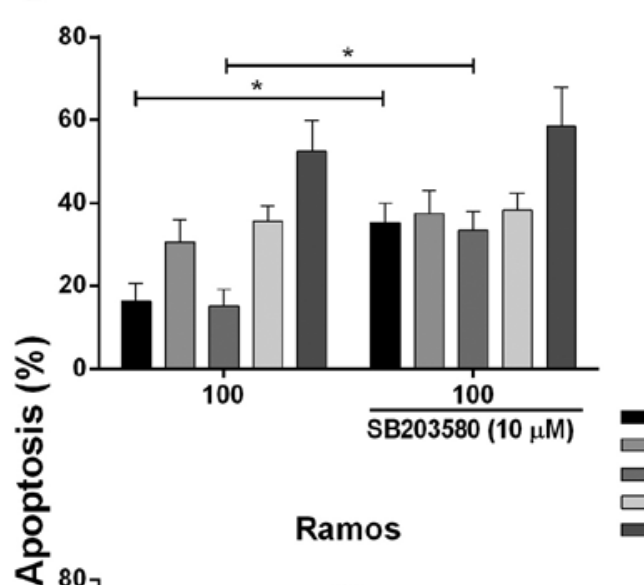

$\square \operatorname{Rxb}$ Rxb + IFN- $\alpha$ $\square$ Fusion IgG + Doxo
Rxb + Doxo Rxb + IFN- $\alpha$ + Doxo $\square$ Fusion + Doxo

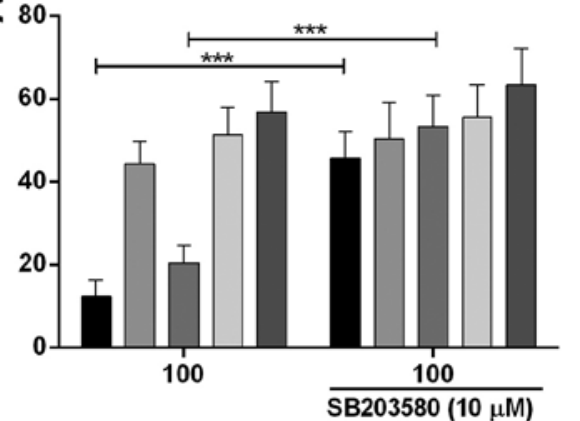

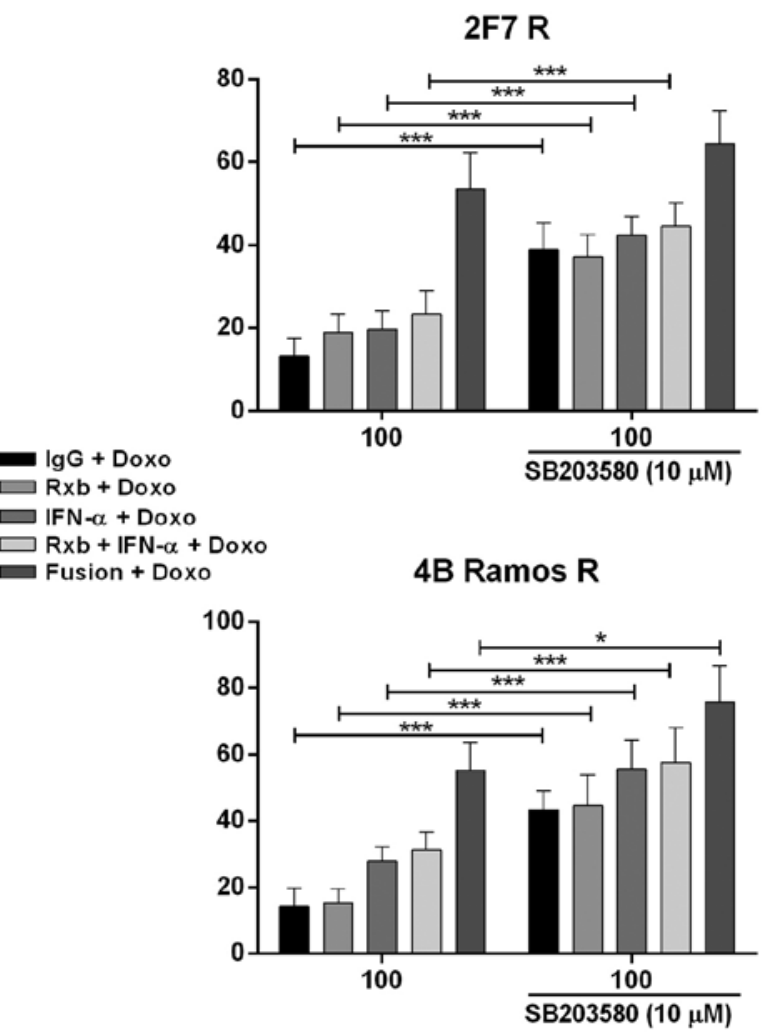

Protein concentration (pM)

Figure 4. Effect of treatment of Ramos and Ramos R with the inhibitors Rottlerin or SB203580 on chemosensitization by anti-CD20/hIFN- $\alpha$ to drug apoptosis (A) Rottlerin-mediated inhibitory effect on chemosensitivity of B-NHL cells by anti-CD20/IFN- $\alpha$ and CDDP. 2F7, 2F7 R, Ramos and Ramos R cells were cultured in the presence or absence of rotterin $(1 \mu \mathrm{M})$ in combination with normal IgG control, rituximab or anti-CD20/IFN- $\alpha$ at indicated concentrations for $12 \mathrm{~h}$ and the treated with or without CDDP $(10 \mu \mathrm{g} / \mathrm{ml})$ for an additional $24 \mathrm{~h}$ and apoptosis was determined as described in Materials and methods. The graph displays the mean \pm SD of three independent experiments. (B) Treatment with SB203580 sensitizes the cells to apoptosis by doxorubicin. The B-NHL cell lines 2F7, 2F7 R. Ramos and Ramos R cells were treated with SB203580 $(10 \mu \mathrm{M})$ for $24 \mathrm{~h}$ in the presence or absence of normal IgG, rituximab, anti-CD20/IFN- $\alpha$ and doxorubicin was added for an additional $24 \mathrm{~h}$. Apoptosis was determined as described in Materials and methods. The data represent the mean \pm SD of 3 experiments. 


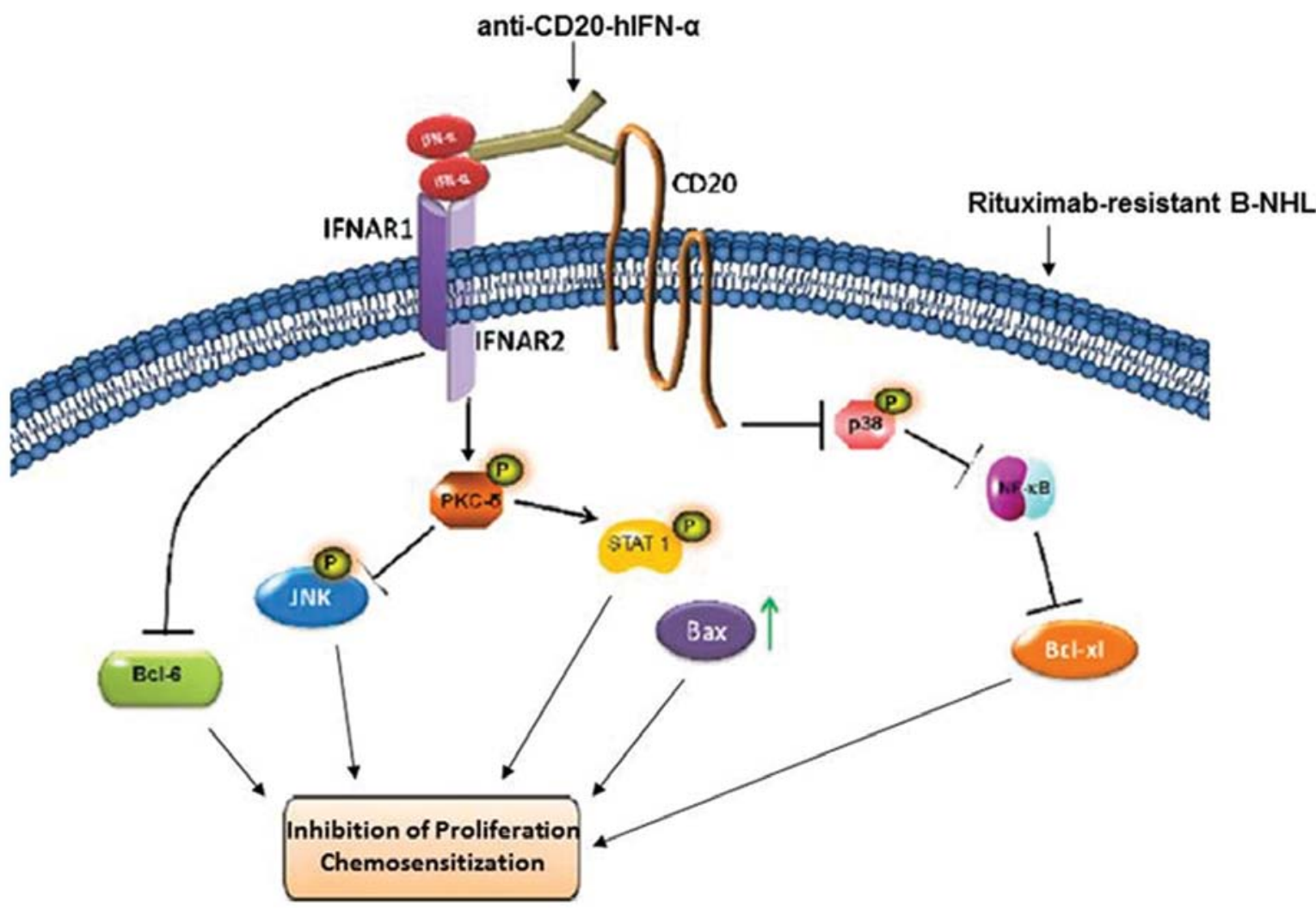

Figure 5. Schematic diagram representing the mechanism by which the anti-CD20-hIFN- $\alpha$ fusion protein sensitizes rituximab-resistant B-NHL cells to chemotherapeutic drugs. Treatment of the RR clones with hIFN- $\alpha$ resulted in the cell signaling mediated by both antiCD20 and by hIFN- $\alpha$. The cell signaling by anti-CD20-hIFN- $\alpha$ resulted in the inhibition of p38 MAPK activity and inhibition of NF-אB activity. These resulted in the downstream inhibition of Bcl- $\mathrm{xL}$ and resulting in the inhibition of cell proliferation and chemosensitization. The cell signaling by hIFN- $\alpha$ resulted in the inhibition of PKC- $\delta$ activity and in the inhibition of JNK activity and induction of Stat 1 and Bax, thus resulting in the inhibition of proliferation and chemosensitization. Clearly, the effects of both anti-CD20 and hIFN- $\alpha$ merged and potentiated the inhibition of proliferation and chemosensitzation.

effective. The anti-CD20-hIFN- $\alpha$-mediated antitumor effects on the RR clones resulted from the independent cell signaling pathways triggered by the fusion protein whereby both anti-CD20 and hIFN- $\alpha$ contributed to the antitumor activity. These findings provide a new potential therapeutic application of anti-CD20 IFN- $\alpha$ for the treatment of patients who are initially unresponsive or become refractory to treatment with rituximab monotherapy or combination of rituximab with chemotherapy.

As previously observed, the anti-CD20-hIFN- $\alpha$ fusion protein was shown to exert greater anti-proliferative and cytotoxic effects on rituximab sensitive lines compared with treatment with either single agent alone or with the combination of anti-CD20 and IFN- $\alpha$ (19). Of interest, the level of apoptosis achieved by anti-CD20-hIFN- $\alpha$ on the RR clones was higher than that achieved on the parental wild-type cells. Previously, we have reported that the potent activity of the fusion protein against human lymphoma cells is dependent on targeting IFN- $\alpha$ to the IFN- $\alpha$ receptor on the tumor cell surface. In addition, we have shown that the RR clones have high levels of IFN- $\alpha \mathrm{R}$ compared to the wild-type parental cell lines (19).

We have reported that treatment of sensitive, but drugresistant B-NHL cell lines, with rituximab were sensitized to various chemotherapeutic drugs and synergy was achieved (20). We now demonstrate that the combination of
anti-CD20-hIFN- $\alpha$ and chemotherapeutic drugs [CDDP, doxorubicin and bendamustine (Treanda)] resulted in reversal of rituximab and drug resistance of RR clones to apoptosis.

Examination of the intracellular pathways, that may be implicated in the sensitization, we showed that the treatment of RR clones with anti-CD20-hIFN- $\alpha$ resulted in the inhibition of both the p38 MAPK and NF- $\kappa$ B pathways. These findings are reminiscent to those previously observed following treatment of wild-type cells with rituximab $(20,23,24)$. These findings suggested that treatment of RR cells with anti-CD20-hIFN- $\alpha$ resulted in the recovery of the cell signaling mediated by rituximab in the parental wild-type cells: this recovery, however, required that anti-CD20 is physically linked to IFN- $\alpha$.

The interaction of IFN- $\alpha$ with its receptor results in the phosphorylation of receptor-associated janus kinases (JAK1 and Tyk2) and leading to the activation of signal transducer activators of transcription (STAT) $(26,27)$ and in B lymphoma cells it induced the activation of JNK1 via PKC- $\delta$ (17). In addition, recent results identified type I IFNs as the first group of cytokines that can downregulate Bcl-6 expression directly in germinal center (GC) B cells (28). In B cells, Bcl-6 modulates both the activation and apoptosis, in addition to controlling DNA-damage sensing and response (29). The phosphorylation of Bcl- 6 protein induces its subsequent degradation by the ubiquitin-proteasome pathway $(30,31)$. Inhibition of Bcl-6 arrests the proliferation and induces apoptosis in B-NHL 
cell lines (32), through the regulation of MAPK and NF- $\kappa \mathrm{B}$ pathways; thus, this link between the inhibition of Bcl-6 and $\mathrm{NF}-\kappa \mathrm{B}$ can explain, in part, the inhibition of $\mathrm{NF}-\kappa \mathrm{B}$ mediated by the fusion protein.

We also explored the role IFN- $\alpha$ in cell signaling by the fusion protein. We observed induction of $\mathrm{p}-\mathrm{PKC}-\mathrm{\delta}$ in both the wild-type and the RR cells by the fusion protein, but not by rituximab. Treatment with the PKC inhibitor rottlerin reversed the chemosensitizing effects of anti-CD20-hIFN- $\alpha$, findings that are consistent with p-PKC- $\delta$ playing a role in the reversal of resistance. Clearly, IFN- $\alpha$ signals the cells by activation of p-JNK, however, in the present findings, there was no effect by the fusion protein on this activity in either the wild-type or the RR clones. In addition, treatment with anti-CD20-hIFN- $\alpha$ resulted in the inhibition of $\mathrm{Bcl}_{-\mathrm{XL}}$ and $\mathrm{Bcl}-6$ and the induction of Bax, gene products that regulate apoptosis and that might play a direct role in the chemosensitization observed by the treatment of the RR clones with anti-CD20-hIFN- $\alpha$.

In addition, the role of $\mathrm{p} 38$ MAPK inhibition by anti-CD20hIFN- $\alpha$ on chemosensitization was corroborated by the use of the p38 inhibitor, SB203580, which mimicked anti-CD20hIFN- $\alpha$ in the reversal of drug resistance in the RR clones. Therefore, the anti-CD20-hIFN- $\alpha$-mediated inhibition of p38 MAPK and $\mathrm{NF}_{-} \kappa \mathrm{B}$ and target genes such as $\mathrm{Bcl}_{-\mathrm{XL}}$, Bcl-6, p-Stat-1 and p-PKC- $\delta$ appear to play a role in the reversal of drug resistance.

CD20 is a membrane-associated non-glycosylated phosphoprotein expressed on the surface of all mature B-cells, and it plays a key role in the development and differentiation of B-cells into plasma cells. The natural CD20 ligand is still unknown, its function is suspected to be similar to a calcium channel in the cell membrane (33). Recently, it was suggested that CD20 may play a central role in the generation of the T-cell-independent antibody response (34). In addition, recent data suggest that CD20-Ab or rituximab potentiates B lymphocytes for the production of interferon (35). In some studies, an additive or synergistic activity of INF with rituximab has been reported in the treatment of lymphomas (10). This relationship between CD20 and IFN may contribute to the efficacy of the anti-CD20-hIFN- $\alpha$ fusion protein. Alternatively, crosslinking with CD20 may prevent the internalization or downregulation of the IFN receptors, resulting in a more prolonged and effective IFN- $\alpha$-induced signal. The mechanism by which anti-CD20-hIFN- $\alpha$ may be acting on the RR clones is not completely understood.

CD20 is constitutively associated to lipid rafts and this association depends on cholesterol and a short membraneproximal cytoplasmic sequence (36). The presence of a dynamic interplay between the neutral glycosphingolipid CD77 and CD20 in B cell lymphomas has been reported (37). Cross-linking of CD77 with SLT-1 induces colocalization with BCR and CD20 in Ramos cells resulting in a regulation of Lyn kinase activity and an increase of the accessibility of the monoclonal Ab to CD20 (38). The above findings could indicate the possible interaction at the cell surface of CD20 and CD77 and this interaction can modulate the accessibility and the CD20 molecular signaling-mediated antibodies. CD77 has been implicated to play a role in IFN- $\alpha$ signal transduction (39). The roles of CD77 in IFN and CD20 signaling may be mediated through interactions between
CD77, the intracellular domains of CD20 and the IFNR-1 of the IFN- $\alpha$ receptor as observed on other proteins, such as CD19 (40). This observation suggests a role for the IFNR/ CD77/CD20 interactions on the cytotoxic effect of the antiCD20-hIFN- $\alpha$ on B-NHL cells. Anti-CD20-hIFN- $\alpha$ is more potent and effective than either IFN- $\alpha$ or anti-CD20 alone or their combination, suggesting that the cross-linking between the IFN receptor and CD20 signaling can potentiate its effect, probably mediated by CD77 interactions. We and others have previously reported that targeting IFN- $\alpha$ to CD20 on B-cell lymphomas resulted in high potency and efficacy in vitro and in vivo models $(19,41,42)$.

The anti-CD20-IFN- $\alpha$ fusion protein induced the activation of PKC- $\delta$, which is involved, in part, in the chemosensitization as shown here in the RR B-NHL cells treated with the PKC- $\delta$ inhibitor rottlerin. Furthermore, since PKC- $\delta$ was hyper-phosphorylated in Ramos R cells, its inhibition only partially decreased the drug-induced apoptosis suggesting that PKC- $\delta$ activation alone is not sufficient for the antiproliferative and proapoptotic actions of the anti-CD20-IFN- $\alpha$ fusion protein. Related studies have demonstrated that $\mathrm{PKC}-\delta$ has multiple targets in response to apoptotic stimuli, including IFN- $\alpha$ (43-46). For example, it has been shown that PKC- $\delta$ mediated the activation of caspase-3 (45) and activation of Bax (47). Our results show that the treatment with the anti-CD20-IFN $\alpha$ fusion protein induced high expression of Bax in Ramos R cells. The classical type 1 IFNs pathway included JAK/STAT activation (26). For instance, IFN- $\alpha$ induced prolonged JNK1 activation (48) with subsequent Stat-1 Ser 727 phosphorylation at least through PKC- $\delta$ signaling $(17,49)$. Stat-1 activation favors the induction of apoptosis (50). We analyzed the activation of JNK/Stat-1 pathway after fusion protein treatment and the activation of these proteins was observed, further suggesting that the classical JNK/Stat-1 activation plays a role in the action of the anti-CD20-IFN- $\alpha$ against RR B-NHL cells.

Clearly, the present findings (schematically diagrammed in Fig. 5) using RR B-NHL cell lines need to be validated with tumor derived RR B-NHL cells in both untreated patients and patients resistant to treatment. In addition, the findings need also to be validated in vivo on the antitumor effect of antiCD20 in mice bearing RR tumor xenografts as monotherapy and in combination with drug therapy. The findings suggest new therapeutic options for the treatment of refractory B-NHL cells or CD20-mediated diseases that no longer respond to rituximab and its combination with chemotherapeutic drugs. Such an application clearly would be targeted and possibly less toxic overall.

\section{Acknowledgements}

This study was supported in part by academic support from the Grant FIS/IMSS/PROT/G13/1191 from the IMSS R-2013-785-029 (M.I.V.), CONACYT (275373) (G.G.V.), Jonsson Comprehensive Cancer Center (M.I.V.), UCLA AIDS Institute (M.I.V.), and Fogarty International Center Fellowship (D43 TW00013-14) (M.I.V. and S.H.-Y.). The authors acknowledge the technical assistance of Andrea Garcia-Olin in the experiments and the assistance of Melissa Cao in the preparation of the manuscript. This study was also supported 
by various donors (B.B.) and by the Johnson Comprehensive Cancer Center at UCLA (B.B.).

\section{References}

1. Siegel R, Ward E, Brawley O and Jemal A: Cancer statistics, 2011: The impact of eliminating socioeconomic and racial disparities on premature cancer deaths. CA Cancer J Clin 61 212-236, 2011.

2. Zelenetz AD, Abramson JS, Advani RH, Andreadis CB, Byrd JC, Czuczman MS, Fayad L, Forero A, Glenn MJ, Gockerman JP, et al: NCCN Clinical Practice Guidelines in Oncology: nonHodgkin's lymphomas. J Natl Compr Canc Netw 8: 288-334, 2010 .

3. Coiffier B, Thieblemont C, Van Den Neste E, Lepeu G, Plantier I, Castaigne S, Lefort S, Marit G, Macro M, Sebban C, et al: Long-term outcome of patients in the LNH-98.5 trial, the first randomized study comparing rituximab-CHOP to standard CHOP chemotherapy in DLBCL patients: A study by the Groupe d'Etudes des Lymphomes de l'Adulte. Blood 116: 2040-2045, 2010.

4. Glennie MJ, French RR, Cragg MS and Taylor RP: Mechanisms of killing by anti-CD20 monoclonal antibodies. Mol Immunol 44: 3823-3837, 2007.

5. Rezvani AR and Maloney DG: Rituximab resistance. Best Pract Res Clin Haematol 24: 203-216, 2011.

6. Vega MI, Martinez-Paniagua M, Jazirehi AR, Huerta-Yepez S, Umezawa K, Martinez-Maza O and Bonavida B: The NF-kappaB inhibitors (bortezomib and DHMEQ) sensitise rituximab-resistant AIDS-B-non-Hodgkin lymphoma to apoptosis by various chemotherapeutic drugs. Leuk Lymphoma 49: 1982-1994, 2008.

7. Shimizu R, Kikuchi J, Wada T, Ozawa K, Kano Y and Furukawa Y: HDAC inhibitors augment cytotoxic activity of rituximab by upregulating CD20 expression on lymphoma cells. Leukemia 24: 1760-1768, 2010.

8. Kimby E: Biological therapy doublets: Pairing rituximab with interferon, lenalidomide, and other biological agents in patients with follicular lymphoma. Curr Hematol Malig Rep 7: 221-227, 2012.

9. Wahlin BE, Sundström C, Holte H, Hagberg H, Erlanson M, Nilsson-Ehle H, Lindén O, Nordström M, Ostenstad B, Geisler $\mathrm{CH}$, et al: $\mathrm{T}$ cells in tumors and blood predict outcome in follicular lymphoma treated with rituximab. Clin Cancer Res 17: 4136-4144, 2011

10. Davis TA, Maloney DG, Grillo-López AJ, White CA Williams ME, Weiner GJ, Dowden S and Levy R: Combination immunotherapy of relapsed or refractory low-grade or follicular non-Hodgkin's lymphoma with rituximab and interferon-alpha-2a. Clin Cancer Res 6: 2644-2652, 2000.

11. Sacchi S, Federico M, Vitolo U, Boccomini C, Vallisa D, Baldini L, Petrini M, Rupoli S, Di Raimondo F, Merli F, et al; GISL: Clinical activity and safety of combination immunotherapy with IFN-alpha $2 \mathrm{a}$ and Rituximab in patients with relapsed low grade non-Hodgkin's lymphoma. Haematologica 86: 951-958, 2001

12. Kimby E, Jurlander J, Geisler C, Hagberg H, Holte H, Lehtinen T, Ostenstad B, Hansen M, Osterborg A, Lindén O, et al; Nordic Lymphoma Group: Long-term molecular remissions in patients with indolent lymphoma treated with rituximab as a single agent or in combination with interferon alpha-2a: A randomized phase II study from the Nordic Lymphoma Group. Leuk Lymphoma 49: 102-112, 2008.

13. Chawla-Sarkar M, Lindner DJ, Liu YF, Williams BR, Sen GC, Silverman RH and Borden EC: Apoptosis and interferons: Role of interferon-stimulated genes as mediators of apoptosis. Apoptosis 8: 237-249, 2003.

14. Hayashida M, Hoshika A, Kanetaka Y, Yanase N and Mizuguchi J: IFN-alpha sensitizes daudi B lymphoma cells to anti-IgM induced loss of mitochondrial membrane potential through activation of c-Jun NH(2)-terminal kinase. J Interferon Cytokine Res 26: 421-429, 2006.

15. Gutterman JU: Cytokine therapeutics: Lessons from interferon alpha. Proc Natl Acad Sci USA 91: 1198-1205, 1994

16. Spielberger RT, Mick R, Ratain MJ and Golomb HM: Interferon treatment for hairy cell leukemia. An update on a cohort of 69 patients treated from 1983 to 1986. Leuk Lymphoma 14 (Suppl 1): 89-93, 1994.
17. Yanase N, Hayashida M, Kanetaka-Naka Y, Hoshika A and Mizuguchi J: PKC- $\delta$ mediates interferon- $\alpha$-induced apoptosis through c-Jun $\mathrm{NH}(2)$-terminal kinase activation. BMC Cell Biol 13: 7-15, 2012

18. Schrama D, Reisfeld RA and Becker JC: Antibody targeted drugs as cancer therapeutics. Nat Rev Drug Discov 5: 147-159, 2006.

19. Xuan C, Steward KK, Timmerman JM and Morrison SL: Targeted delivery of interferon-alpha via fusion to anti-CD20 results in potent antitumor activity against B-cell lymphoma. Blood 115: 2864-2871, 2010.

20. Jazirehi AR, Vega MI and Bonavida B: Development of rituximab-resistant lymphoma clones with altered cell signaling and cross-resistance to chemotherapy. Cancer Res 67: 1270-1281, 2007.

21. Vega MI, Huerta-Yepez S, Martinez-Paniagua M, MartinezMiguel B, Hernandez-Pando R, González-Bonilla CR, Chinn P, Hanna N, Hariharan K, Jazirehi AR, et al: Rituximab-mediated cell signaling and chemo/immuno-sensitization of drug-resistant B-NHL is independent of its Fc functions. Clin Cancer Res 15: 6582-6594, 2009.

22. Alas S, Emmanouilides C and Bonavida B: Inhibition of interleukin 10 by rituximab results in down-regulation of bcl-2 and sensitization of B-cell non-Hodgkin's lymphoma to apoptosis. Clin Cancer Res 7: 709-723, 2001.

23. Bonavida B: Rituximab-induced inhibition of antiapoptotic cell survival pathways: Implications in chemo/immunoresistance, rituximab unresponsiveness, prognostic and novel therapeutic interventions. Oncogene 26: 3629-3636, 2007.

24. Vega MI,Huerta-Yepaz S, Garban H, Jazirehi A,Emmanouilides C and Bonavida B: Rituximab inhibits p38 MAPK activity in 2F7 B NHL and decreases IL-10 transcription: Pivotal role of p38 MAPK in drug resistance. Oncogene 23: 3530-3540, 2004.

25. Czuczman MS and Gregory SA: The future of CD20 monoclonal antibody therapy in B-cell malignancies. Leuk Lymphoma 51: 983-994, 2010.

26. Kotenko SV and Pestka S: Jak-Stat signal transduction pathway through the eyes of cytokine class II receptor complexes. Oncogene 19: 2557-2565, 2000.

27. Stark GR, Kerr IM, Williams BR, Silverman RH and Schreiber RD: How cells respond to interferons. Annu Rev Biochem 67: 227-264, 1998.

28. Salamon D, Adori M, He M, Bönelt P, Severinson E, Kis LL, Wu L, Ujvari D, Leveau B, Nagy N, et al: Type I interferons directly down-regulate BCL-6 in primary and transformed germinal center B cells: Differential regulation in B cell lines derived from endemic or sporadic Burkitt's lymphoma. Cytokine 57: 360-371, 2012.

29. Basso K, Saito M, Sumazin P, Margolin AA, Wang K, Lim WK, Kitagawa Y, Schneider C, Alvarez MJ, Califano A, et al: Integrated biochemical and computational approach identifies BCL6 direct target genes controlling multiple pathways in normal germinal center B cells. Blood 115: 975-984, 2010.

30. Niu H, Ye BH and Dalla-Favera R: Antigen receptor signaling induces MAP kinase-mediated phosphorylation and degradation of the BCL-6 transcription factor. Genes Dev 12: 1953-1961, 1998.

31. Phan RT, Saito M, Kitagawa Y, Means AR and Dalla-Favera R: Genotoxic stress regulates expression of the proto-oncogene Bcl6 in germinal center B cells. Nat Immunol 8: 1132-1139, 2007.

32. Basso K and Dalla-Favera R: Roles of BCL6 in normal and transformed germinal center B cells. Immunol Rev 247: 172-183, 2012.

33. Cragg MS, Walshe CA, Ivanov AO and Glennie MJ: The biology of CD20 and its potential as a target for mAb therapy. Curr Dir Autoimmun 8: 140-174, 2005

34. Kuijpers TW, Bende RJ, Baars PA, Grummels A, Derks IA, Dolman KM, Beaumont T, Tedder TF, van Noesel CJ, Eldering E, et al: CD20 deficiency in humans results in impaired T cell-independent antibody responses. J Clin Invest 120: 214-222, 2010.

35. Xu D, Staedman A and Zhang L: CD20 antibody primes B lymphocytes for type I interferon production. PLoS One 8: e67900, 2013.

36. Polyak MJ, Tailor SH and Deans JP: Identification of a cytoplasmic region of CD20 required for its redistribution to a detergent-insoluble membrane compartment. J Immunol 161: 3242-3248, 1998.

37. Jarvis RM, Chamba A, Holder MJ, Challa A, Smith DC, Hodgkin MN, Lord JM and Gordon J: Dynamic interplay between the neutral glycosphingolipid CD77/Gb3 and the therapeutic antibody target CD20 within the lipid bilayer of model B lymphoma cells. Biochem Biophys Res Commun 355: 944-949, 2007. 
38. Holder MJ, Chamba A, Hardie DL, Deans JP and Gordon J: Improved access to CD20 following B cell receptor cross-linking at Burkitt's lymphoma cell surfaces. Leuk Res 28: 1197-1202, 2004.

39. Khine AA and Lingwood CA: Functional significance of globotriaosyl ceramide in interferon-alpha(2)/type 1 interferon receptor-mediated antiviral activity. J Cell Physiol 182: 97-108, 2000.

40. Maloney MD, Binnington-Boyd B and Lingwood CA: Globotriaosyl ceramide modulates interferon-alpha-induced growth inhibition and CD19 expression in Burkitt's lymphoma cells. Glycoconj J 16: 821-828, 1999.

41. Rossi EA, Goldenberg DM, Cardillo TM, Stein R and Chang CH: CD20-targeted tetrameric interferon-alpha, a novel and potent immunocytokine for the therapy of B-cell lymphomas. Blood 114: 3864-3871, 2009.

42. Rossi EA, Rossi DL, Stein R, Goldenberg DM and Chang $\mathrm{CH}$ : A bispecific antibody-IFNalpha2b immunocytokine targeting CD20 and HLA-DR is highly toxic to human lymphoma and multiple myeloma cells. Cancer Res 70: 7600-7609, 2010.

43. Brodie $\mathrm{C}$ and Blumberg PM: Regulation of cell apoptosis by protein kinase c delta. Apoptosis 8: 19-27, 2003.

44. Jackson DN and Foster DA: The enigmatic protein kinase Cdelta: Complex roles in cell proliferation and survival. FASEB J 18: 627-636, 2004.
45. Reyland ME: Protein kinase Cdelta and apoptosis. Biochem Soc Trans 35: 1001-1004, 2007.

46. Saijo K, Mecklenbräuker I, Schmedt C and Tarakhovsky A: B cell immunity regulated by the protein kinase C family. Ann NY Acad Sci 987: 125-134, 2003.

47. Yanase N, Ohshima K, Ikegami H and Mizuguchi J: Cytochrome $c$ release, mitochondrial membrane depolarization, caspase-3 activation, and Bax-alpha cleavage during IFN-alpha-induced apoptosis in Daudi B lymphoma cells. J Interferon Cytokine Res 20: 1121-1129, 2000.

48. Yanase N, Hata K, Shimo K, Hayashida M, Evers BM and Mizuguchi J: Requirement of c-Jun NH2-terminal kinase activation in interferon-alpha-induced apoptosis through upregulation of tumor necrosis factor-related apoptosis-inducing ligand (TRAIL) in Daudi B lymphoma cells. Exp Cell Res 310: 10-21, 2005.

49. Kaur S, Parmar S, Smith J, Katsoulidis E, Li Y, Sassano A, Majchrzak B, Uddin S, Tallman MS and Fish EN: Role of protein kinase C-delta (PKC-delta) in the generation of the effects of IFN-alpha in chronic myelogenous leukemia cells. Exp Hematol 33: 550-557, 2005.

50. Kumar A, Commane M, Flickinger TW, Horvath CM and Stark GR: Defective TNF-alpha-induced apoptosis in STAT1null cells due to low constitutive levels of caspases. Science 278: 1630-1632, 1997. 